\title{
Prosocial Response to Client-Instigated Victimization: \\ The Roles of Forgiveness and Workgroup Conflict
}

\author{
Jonathan E. Booth \\ Tae Youn Park \\ Luke (Lei) Zhu \\ T. Alexandra Beauregard \\ Fan $\mathrm{Gu}$ \\ Cécile Emery
}

Accepted October 27. 2017

Booth, J. E., Park, T. Y., Zhu, L., Beauregard, T. A., Gu, F., \& Emery, C. (2017). Prosocial response to client-instigated victimization: The roles of forgiveness and workgroup conflict. Forthcoming in Journal of Applied Psychology. doi: 10.1037/apl0000286

(C) 2017, American Psychological Association. This paper is not the copy of record and may not exactly replicate the final, authoritative version of the article. Please do not copy or cite without authors’ permission. The final article will be available, upon publication, via its DOI:

10.1037/apl0000286 


\title{
Prosocial Response to Client-Instigated Victimization: The Roles of Forgiveness and Workgroup Conflict
}

\begin{abstract}
We investigate forgiveness as a human service employee coping response to clientinstigated victimizations and further explore the role of workgroup conflict in 1) facilitating this response, and 2) influencing the relationship between victimization and workplace outcomes. Using the theoretical lens of Conservation of Resources (Hobfoll, 1989), we propose that employees forgive clients - especially in the context of low workgroup conflict. From low to moderate levels of client-instigated victimization, we suggest that victimization and forgiveness are positively related; however, this positive relationship does not prevail when individuals confront egregious levels of victimization (i.e., an inverted-U shape). This curvilinear relationship holds under low but not under high workgroup conflict. Extending this model to workplace outcomes, findings also demonstrate that the indirect effects of victimization on job satisfaction, burnout, and turnover intentions are mediated by forgiveness when workgroup conflict is low. Experiment- and field-based studies provide evidence for the theoretical model.
\end{abstract}

Keywords: client-instigated victimization, forgiveness, workgroup conflict, human service employees 
The human service sector (e.g., nurses, caregivers, therapists, teachers, social workers) is one of the fastest growing segments of the US economy (Bureau of Labor Statistics, 2014). As the demand for human service work has increased, so has the frequency of clients victimizing these employees (Rasmussen, Hogh, \& Andersen, 2013; Terry, 1998). Victimization is an “individual’s self-perception of having been exposed, either momentarily or repeatedly, to aggressive acts emanating from one or more other persons” (Aquino \& Bradfield, 2000, p. 526). Aggressive acts can be either psychologically or physically injurious (Aquino \& Lamertz, 2004), and their negative impact on employee wellbeing, job satisfaction and performance has implications for client care (e.g., Arnetz \& Arnetz, 2001). Human service employees have been found to respond to client victimization by avoiding or escaping from perpetrators (Leiter, 1991), withdrawing from client-focused work tasks, and becoming callous toward perpetrators (for a review, see Needham, Abderhalden, Halfens, Fischer, \& Dassen, 2005). All of these coping strategies are undesirable to employers because they compromise the client-employee relationship, violate a "professional service script” that requires employees to be pleasant, considerate, and competent, and can cause reputational and financial harm to the employer (Grandey, Dickter, \& Sin, 2004; Wang, Liao, Zhan, \& Shi, 2011). For human service employees, antisocial coping responses also violate the code of ethics governing their interactions with clients (who are often vulnerable), complicate caregiving, and do not promote client well-being.

In the broader customer-instigated victimization literature, investigation has placed emphasis on victimized service providers' antisocial or maladaptive responses to customers, such as sabotage or revenge (e.g., Skarlicki, van Jaarsveld, \& Walker, 2008; Yagil, 2008). However, scholarly evidence illustrates that victimized employees do not necessarily react negatively, but sometimes choose to forgive their transgressors (Aquino, Tripp, \& Bies, 2006; Bradfield \& 
Aquino, 1999; Cox, Bennett, Tripp, \& Aquino, 2012). Given the importance of being prosocial in a service providing role, especially human service work, oddly there has been little focus in understanding such prosocial coping approaches to client transgressions. In light of the above, we contribute to this paucity of research by presenting forgiveness as an alternative, prosocial and effective strategy that human service employees can use to cope with victimization while still maintaining their service script and code of conduct requirements.

Our further contributions to the literature are fivefold. First, as forgiveness requires cognitive control to implement, and this is a depletable resource (van der Wal, Karremans, \& Cillessen, 2012), we adopt Conservation of Resources (COR; Hobfoll, 1989; 2002) theory to conceptualize and predict forgiveness as a coping mechanism with resource-related implications. Second, evidence has shown that victims who are close to their perpetrators or who are concerned about breaching social or moral standards are likely to forgive, yet the literature also has demonstrated that the egregiousness of perpetrators' actions is negatively related to forgiveness (Fehr, Gelfand, \& Nag, 2010). Although these associations with forgiveness are in opposite linear directions, we suggest that they have the potential to function together. Human service employees who are close and committed to their clients may be motivated to use cognitive control resources to transform negative emotions into more positive emotions to forgive. Yet, at egregious levels of abuse, forgiveness may be too demanding to warrant resource use. Therefore, we extend previous scholarly work suggesting that employees do not forgive uniformly (e.g., Aquino et al., 2006) and propose that the victimization-forgiveness relationship is curvilinear (i.e., inverted U-shaped), rather than linear.

Additionally, previous work has discussed that context matters as a precursor to forgiveness (Fehr \& Gelfand, 2012; Fehr et al., 2010; Finkel, Rusbbult, Kumashiro, \& Hannon, 
2002), but knowledge is limited, especially in the workplace literature, of contextual moderators that inhibit or enhance forgiveness. An exception is Aquino et al.’s (2006) study that shows that forgiveness increases under conditions of high procedural justice, and decreases under conditions of low procedural justice. We add to existing knowledge of boundary conditions for forgiveness by investigating the moderating role of workgroup conflict, a key stressor for human service workers (e.g., Almost, Doran, McGillis Hall, \& Spence Laschinger, 2010). As high workgroup conflict has potential to compete for available cognitive control resources to regulate negative emotions, we question whether victimized employees would be able or willing to forgive clientinstigated victimizations under these conditions and further posit that the curvilinear victimization-forgiveness relationship may only prevail under low workgroup conflict.

Our final contribution comprises two facets. The literature provides knowledge regarding consequences of forgiveness, such as relationship quality and individual health and wellbeing (e.g., Bono, McCullough \& Root, 2008; Witvliet, Ludwig, \& Laan, 2001). However, this evidence originates from non-work domains, and we have limited knowledge of "the consequences of forgiveness in the context of workplace victimization” (Aquino \& Thau, 2009, p. 732; for an exception, see Cox et al., 2012). If forgiveness happens in the workplace, it is important to know its implications for the employee and employer. Hence, we contribute to the dearth of research on workplace outcomes of forgiveness by specifically investigating forgiveness' relationship with employee burnout, job satisfaction, and turnover intentions. Lastly, as mentioned, the previous literature has generally explored forgiveness as an antecedent or consequence. We contribute to the literature by investigating forgiveness as a mediating mechanism, rather than simply a correlate or main effect (Fehr et al., 2010; Riek \& Mania, 2011). We demonstrate indirect relationships between victimization and burnout, job 
satisfaction, and turnover intentions, through forgiveness, under conditions of low workgroup conflict. Figure 1 depicts our theoretical model. We present experiment- and field-based evidence to support our model's predictions.

Insert Figure 1 about here

\section{Theoretical Background}

\section{Conservation of Resources: Forgiveness}

Hobfoll's (1989, 2002) COR theory posits that individuals make an effort to obtain, retain, and protect resources, especially resources that they personally value and are central to fulfilling their core needs and objectives. According to COR theory, stress is experienced after negative events if resources have been threatened, lost, and/or not gained after significant previous investment. COR theory proposes that resource threat and loss place demands on individuals, and are more salient than resource gain (Alarcon, 2011; Hobfoll, 2011).

From this perspective, exposure to victimization can threaten an individual's resources (e.g., Cox, Johnson, \& Coyle, 2015), which subsequently motivates an individual to engage in coping strategies to stop further resource loss and/or to regain resources in efforts to avoid psychological distress and burnout (Hobfoll \& Shirom, 1993; Ito \& Brotheridge, 2003; Schaufeli \& Buunk, 2003). Coping strategies refer to affective, cognitive, or behavioral "efforts to manage specific external and/or internal demands that are appraised as taxing or exceeding the resources of the person” (Lazarus \& Folkman, 1984, p. 141). These coping strategies are often categorized in the literature as either problem-focused (i.e., action coping to relieve the problem) or emotionfocused (i.e., emotion-regulation oriented coping to lessen emotional distress; see Lazarus \& Folkman, 1984). When individuals have few resources at their disposal to meet high demands, 
they enlist maladaptive coping options that are ineffective in regaining resources and preventing loss and that ultimately lead to negative consequences (Alarcon, 2011; Hobfoll \& Shirom, 1993; Leiter, 1991; Schaufeli \& Buunk, 2003). Alternatively, when resources meet demands and effective coping occurs, individuals are unlikely to experience psychological distress because they resist stress and experience restored well-being (e.g., Leiter, 1991; Hobfoll, 2002; Hobfoll \& Shirom, 1993).

In human service work, coping options are limited given the service script concerns and the mandate to protect and provide caring service to clients that are generally vulnerable. Of the available problem-focused strategies, confrontation is not an ideal response to aggressive clients because it escalates conflict, leads to poor service appraisals, and can cost employees their jobs (Yagil, 2008). While some de-escalatory strategies, such as negotiating, can be effective at placating clients, others may violate organizational rules (e.g., employees giving "gifts” without employer approval) or may be inconsistent with the employee’s moral convictions (e.g., using sex appeal to distract the customer from the source of dissatisfaction; Reynolds \& Harris, 2006). For these reasons, it is likely that human service workers are more engaged in emotion-focused coping to manage their responses to client-instigated victimization (Ben-Zur \& Yagil, 2005). A review of research on aggression in service encounters has identified avoiding stressful interactions, psychologically denying that any negative event occurred, and emotionally distancing oneself from the situation as the most frequently adopted emotion-focused strategies used by service providers (Yagil, 2008), yet these coping strategies also can impede proper service provision and can have negative implications for employees (Ben-Zur \& Yagil, 2005) and client well-being. A human service worker avoiding aggressive clients limits adequate contact required for care fulfillment and likely leads to employee discipline. Denial is 
problematic because it does not necessarily alleviate the negative emotional states caused by client victimization and could lead to other adverse outcomes like burnout and depersonalization (Ben-Zur \& Yagil, 2005). Emotional distancing can leave the employee feeling uninterested in or indifferent to client needs, which does not facilitate the attentiveness required of human service work to perform respectful caregiving that is expected by clients and employers.

Consequently, in this study we adopt COR theory to consider forgiveness as an alternative emotion-focused coping option with resource-related implications for human service employees. Forgiveness is a form of emotion-focused coping in which the victim uses cognitive control resources to transform negative emotions to positive or neutral emotions that are focused on continuing the relationship with the perpetrator (Worthington, 2006; Worthington \& Scherer, 2004). When confronted with victimization, victims innately have a negative emotional response (e.g., fear and anger; Worthington, 2006), and dwelling on the offense and negative emotions develops into negative motivations towards perpetrators (e.g., bitterness, hostility, resentment; Worthington, 2006). However, victims have the potential to change their negative emotions to more positive other-focused emotions (e.g., empathy, compassion, love), and, thus, let go of their negative feelings and forgive their perpetrators (e.g., Sandage \& Worthington, 2010). Forgiveness can therefore be understood as a process of motivational change (McCullough, Fincham, \& Tsang, 2003), in which avoidance and revenge motivations are decreased and benevolent motivation increased (Wilkowski, Robinson, \& Troop-Gordon, 2010).

This motivational process represents a type of cognitive change, one of the broad strategies in Gross’s (1998) process model of emotion regulation. Cognitive change involves selecting which of several potential emotional meanings will be attached to a situation (Gross, 2015), and requires cognitive control resources to implement (Pronk, Karremans, Overbeek, 
Vermulst, \& Wigboldus, 2010; Wilkowski et al., 2010). Cognitive control has been conceptualized as a limited capacity resource that is used to override inappropriate thoughts, urges, and behavior (Wilkowski et al., 2010) by directing attention to regulate and shape cognitions, emotions, and behavior in a goal-directed manner (Payne, 2005). According to conflict monitoring theory (Botvinick, Braver, Barch, Carter, \& Cohen, 2001), cognitive control resources are required to resolve the conflict between two simultaneous but incompatible responses to a transgression, such as the desire for retaliation versus continuation of the client relationship. Wilkowski et al.'s (2010) studies provide evidence that availability of cognitive control resources promotes forgiveness as individuals can transform their aggressive impulses. Additionally, in support of this notion, Karremans and van der Wal (2013) find that individuals who are motivated to maintain interpersonal relationships are more likely to expend cognitive control to reduce negative emotions toward the transgressor, unless these cognitive control resources are temporarily depleted. Further, work by Karremans and Aarts (2007) demonstrates that forgiving is a more effortful process that requires sufficient cognitive control resources such as attention in order to decide to forgive and to implement that decision., especially when the transgressor is not intimately close to the victim, such as a romantic partner or immediate family member.

\section{Victimization and Forgiveness}

“Compassion is an essential element” for human service work (Radey \& Figley, 2007, p. 207) and, thus, is an integral part of employee-client interactions and care delivery (Rynes, Bartunek, Dutton, \& Margolis, 2012). Human service employees generally are trained and socialized by their professional schooling, licensing bodies, and/or employers to respond to clients with understanding and empathetic concern (Brunero, Lamont, \& Coates, 2010; Stephen 
\& Baernstein, 2006). Given that relationships are core to human service work, these employees often identify with their clients and may develop bonds with them (e.g., Vachon \& Müeller, 2009). Scholarly investigation has suggested that victims who have an affinity for their perpetrators have potential to increase their forgiveness efforts even as transgression intensity increases (e.g., McCullough et al., 1998; Pronk et al., 2010). Therefore, human service employees’ baseline approach to handling client-instigated victimizations is likely a compassionate, other-focused strategy (e.g., Hellzen, Asplund, Gilje, Sandman, \& Norberg, 1998), such as forgiveness.

Logically, the efforts that human service employees will make to forgive should be a function of victimization intensity. At very low levels of victimization, the employee is less likely to interpret the client-instigated victimization as harmful and will therefore not be motivated to go through the cognitive and emotional effort that forgiveness requires (Aquino, Grover, Goldman, \& Folger, 2003). However, at higher levels of client-instigated victimization, the likelihood that the victim will experience adverse consequences and want to respond aggressively against perpetrators increases. This is consistent with COR theory, which suggests that as a perceived threat increases, so does an individual's motivation to respond to that threat. Under these conditions, human service workers may attempt forgiveness as a way of trying to maintain a positive relationship with clients while reducing the intensity of their negative emotional state. Indeed, Pronk et al. (2010) showed that individuals who experienced relatively more intense offenses as opposed to low level offenses were more likely to engage in the cognitive efforts required to forgive their perpetrators.

Yet there is obviously some threshold at which the resource-related costs of forgiving those who offend at the most egregious intensities may outweigh the benefits of forgiving, and 
thereby reduce motivation to do so. When victimization is at an egregious level, the strength of negative emotions is likely to be such that transforming them into positive emotions becomes extremely difficult. Consistent with COR theory, when forgiveness is seen as unlikely to be worth the expenditure of effort and cognitive control resources, human service workers may respond by conserving existing resources and deciding not to forgive.

In addition, workers may also lack sufficient resources to forgive egregious victimizations. Egregious client victimizations impair employee cognitive functioning (Rafaeli, Erez, Ravid, Derfler-Rozin, \& Efrat-Treister, 2012) and are especially overwhelming and frustrating to caregivers due to the problems associated and lack of workable solutions (Hellzen et al., 1998). As a result, employees will lack the cognitive control resources necessary to focus attention on replacing their negative emotions with more positive ones (see Groth \& Grandey, 2012; Sliter, Pui, Sliter, \& Jex, 2011). In a qualitative study, psychiatric nurses described encountering patient-instigated victimizations that were so egregious that they deviated from what was considered by the nurses as normal or expected victimization behaviors for their work environment. The nurses labeled these egregious victimizations as abnormal and disturbing and had difficulty in seeing the abusive patient as an actual person (Hellzen, Asplund, Sandman, \& Norberg, 1999). They indicated feeling anguish because they were unable to generate the emotional participation and understanding required to provide good nursing care and instead felt that the care they provided was unacceptable (Hellzen et al., 1999). This evidence illustrates how victimization at the most egregious level is cognitively and emotionally challenging for human service workers by reducing the cognitive control resources required for forgiveness.

Accordingly, the relationship between client-instigated victimization and forgiveness should take on an inverted-U shape (see Grant \& Schwartz, 2011). That is, forgiveness increases 
from low to moderate levels of victimization, but it declines once a critical threshold of victimization is reached. Human service workers exposed to low levels of victimization have little motivation to engage in forgiveness, but those experiencing greater victimization will be more motivated to respond to this threat and will therefore engage in greater forgiveness. Those exposed to the most intense victimizations may view forgiveness as too difficult, and seek to conserve resources by not forgiving. Alternatively, they may focus their full attention on the threat and thus lack the cognitive control resources to transform their negative emotions to more positive ones, thereby engaging in less forgiveness.

Hypothesis 1: There will be an inverted-U shaped relationship between victimization and forgiveness.

\section{Moderating Role of Workgroup Conflict between Victimization and Forgiveness}

Research on forgiveness has generally paid less attention to the role of context as a facilitator or inhibitor of forgiveness than it has to characteristics of the forgiver. However, some scholars have recognized that context matters a great deal for explaining why people forgive (Aquino et al., 2006; Fehr \& Gelfand, 2012; Fehr et al., 2010; Finkel et al., 2002). Jehn (1995) observed that environments promoting increased levels of workgroup conflict "did not provide an atmosphere of ... forgiveness” (p. 275). This observation suggests that workgroup conflict is likely an obstacle for one to change his/her negative emotions to neutral or positive ones.

Workgroup conflict can significantly impact human service employees and their service delivery. Workgroup conflict refers to affective interpersonal tensions and disagreements regarding task-related issues among group members (Jehn, 1995; Jehn \& Mannix, 2001) and has been identified by researchers as one of the most unpleasant and difficult of all workplace stressors (e.g., Jex \& Beehr, 1991). For example, nurses have indicated that workgroup conflict is the most common conflict experienced at work, is a significant source of workplace stress 
(e.g., Farrell, 1999), and contributes to turnover, patient safety and care quality issues (Rowe \& Sherlock, 2005; Spence Laschinger, Leiter, Day, \& Gilin, 2009). Perhaps the main reason why workgroup conflict is so harmful to employees is that regulating negative emotions from these conflicts requires sustained cognitive and emotional exertion that depletes an employee's stock of cognitive control resources (Liu et al., 2015; Sliter et al., 2011). Indeed, Porath and Erez (2007) provided causal evidence that the link between interpersonal conflict and poor performance is mediated by disruption to cognitive resources.

Due to individuals only having a finite amount of cognitive control resources at their disposal (Wilkowski et al., 2010), there is competition between the regulatory demands of workgroup conflict and the regulatory demands of client-instigated victimization, and this competition diminishes the available cognitive control resources for victimized employees to direct their attention to transforming their negative emotions to more positive ones (see Liu et al., 2015). If we are correct in our theorizing, then we should not observe any systematic relationship between client-instigated victimization and forgiveness under high workgroup conflict, as employees in this situation will not have adequate cognitive control resources to execute forgiveness. Conversely, under low workgroup conflict, employees experience relatively fewer cognitive distractions, and correspondingly fewer demands on their available cognitive control resources. These resources are therefore less likely to be at risk (see Liu et al., 2015), leaving human service workers with greater potential to apply cognitive control resources to forgiveness efforts. However, as previously theorized, human service workers may not have the capacity to forgive due to cognitive impairment at egregious victimization levels, or they may perceive the task of forgiveness as too effortful at these levels to be worth the resource expenditure. Hence, even in low conflict workgroups, forgiveness will decrease at egregious victimization levels. 
Hypothesis 2: Workgroup conflict will moderate the curvilinear relationship between victimization and forgiveness such that the relationship will be curvilinear, in the form of an inverted-U, when workgroup conflict is low. When workgroup conflict is high, there will be no effect of victimization on forgiveness.

Having identified one of the conditions under which employees might be less likely to respond to client victimization by forgiving, we now consider the mediating role of forgiveness.

\section{Mediating Role of Forgiveness When Workgroup Conflict Moderates}

The literature is at a nascent stage regarding the impact of forgiveness on workplace outcomes (Aquino \& Thau, 2009). Though there is debate regarding the endpoint to the forgiveness process (Strelan \& Covic, 2006), scholars who ascribe the endpoint of forgiveness from the perspective of the victim propose that forgiveness occurs with cessation of an individual's negative cognition, affect, and/or behavior or behavioral intentions (Gordon \& Baucom, 1998). We explore job satisfaction, burnout, and turnover intentions, which represent cognition, affect, and behavioral intentions respectively. These constructs provide a meaningful way to assess the impact of forgiveness in a human services context where other frequently studied coping outcomes such as work withdrawal (Cortina \& Magley, 2003) may be less appropriate due to a strong service or caretaking ethos preventing employees from decreasing their effort on the job even in the face of mistreatment. Given that forgiveness by definition is at first, and oftentimes only, intrapersonal (i.e., forgiveness does not require interpersonal action), it is imperative that we capture individual workplace cognition, affect, and behavioral intent to understand how the endpoint of forgiveness from the perspective of the victim has workplace implications.

We expect that choosing to forgive in response to client-instigated victimization will help employees maintain more favorable workplace attitudes, decrease the likelihood that they will experience burnout, and make them less inclined to quit the organization. The main reason these 
outcomes will occur is that employees who forgive will experience lower levels of negative emotions and will adopt a generally more positive orientation towards clients, even if they have been victimized by some of them (McCullough et al., 1998). Further, Karremans, Van Lange, and Holland (2005) found that the increased prosocial cognitions, feelings, and behaviors that manifest through forgiveness have a spillover effect on more general attitudes - helping individuals who engage in forgiveness to have a prosocial frame of mind and feelings of relatedness toward others. In contrast, victimized employees who do not forgive will experience more psychological tension and discomfort because of conflicting cognitions and feelings (Karremans, Van Lange, Ouwerkerk, \& Kluwer, 2003), and they are also more likely to retain feelings of anger, resentment, and anxiety as they ruminate on previous victimization experiences (e.g., Worthington \& Scherer, 2004). It seems reasonable to presume that these negative cognitive and emotional states will have a corresponding adverse impact on job-related attitudes, on the employee's ability to cope with workplace demands, and on their desire to remain with their organization.

A key precept of the COR model is that coping with a perceived threat requires resources. Burnout and turnover intentions are often studied in COR research as indications of depleted resources and attempts to conserve resources, respectively (e.g., Campbell, Perry, Maertz, Allen, \& Griffeth, 2013). An adaptive coping approach is one that either requires a lesser expenditure of resources, and/or results in the acquisition of further resources sufficient to offset the initial depletion of resources necessary to execute the coping response (a net gain). While forgiveness depletes cognitive control resources, it yields benefits in terms of positive cognitions, emotions, and behaviors (Karremans et al., 2005), and the positive impact of these on job-related attitudes, well-being, and behavioral intentions thus represents a net gain for employees. A maladaptive 
coping response, in contrast, is one that results in a net loss of resources. Victimized employees who employ antisocial coping responses, such as revenge, are likely to incur costs as they continue to ruminate about the transgressor and experience increased negative affect (e.g., Carlsmith, Wilson, \& Gilbert, 2008), subsequently resulting in more negative outcomes with regard to attitudes, well-being, and behavioral intentions (a net loss; e.g., Bono et al., 2008).

Considering the potential for forgiveness to have positive effects on workplace outcomes, we suggest a victimization-forgiveness-workplace outcome path model which is consistent with stress theoretical perspectives that coping is a mediating link between potential stressors and their outcomes (e.g., Alarcon, 2011; Benight et al., 1999; Hobfoll \& Shirom, 1993; Lazarus \& Folkman, 1984; Leiter, 1991; Schaufeli \& Buunk, 2003). After encountering stressful events, victims are motivated to find coping responses to manage these events (e.g., to regain resources or prevent loss) and avoid negative consequences (Benight et al., 1999; Hobfoll \& Shirom, 1993; Ito \& Brotheridge, 2003; Schaufeli \& Buunk, 2003). Similarly, the forgiveness literature has elaborated the role of forgiveness as an emotion-focused coping strategy that mediates the relationship between stressful events and outcomes (van Rensburg \& Raubenheimer, 2015; Worthington \& Scherer, 2004).

Combining this mediated model with theorizing from Hypothesis 2, we hypothesize that forgiveness mediates the indirect effect between victimization and workplace outcomes (job satisfaction, burnout, turnover intentions) under low workgroup conflict. However, under high workgroup conflict, forgiveness will not occur at any level of victimization and, thus, will not mediate because high workgroup conflict competes for and reduces the available cognitive control resources that victims require to effectively forgive.

When contrasting the anticipated total effects under conditions of low versus high 
workgroup conflict, we propose that the total effects under low workgroup conflict (i.e., the conditional indirect effect between victimization and workplace outcomes via forgiveness) will be attenuated in comparison to the total effects under high workgroup conflict (i.e., the effect between victimization and workplace outcomes without forgiveness mediating), particularly for victimizations at low to moderate levels. Under low workgroup conflict, victims experiencing low to moderate levels of victimization have sufficient available cognitive control resources to direct their attention to transform negative emotions to more positive ones and forgive, and, thus, the benefits of forgiveness can convey to workplace outcomes. Yet, these benefits dissipate under low workgroup conflict and high victimization because victimizations at high levels are cognitively challenging. The cognitive resources required to forgive are either depleted and therefore unavailable, or employees will seek to conserve (rather than expend) resources in the face of increased threat and will therefore lack motivation to forgive. Formally, we hypothesize the following:

Hypothesis 3: The relationship between client-instigated victimization and workplace outcomes (job satisfaction, burnout, turnover intentions) is mediated by forgiveness when workgroup conflict is low. When workgroup conflict is high, forgiveness does not mediate the relationships.

We conducted multiple studies to test our hypotheses. Study 1a experimentally tested our claim that workgroup conflict depletes resources. Next, in Study 1b, we conducted another experiment to ensure the causal ordering of Hypotheses 1 and 2. Then, we conducted Study 2 to test all three hypotheses and to generalize our findings to an actual workplace setting. Study 3 is a constructive replication of Study 2 that allows us to look at effects from a diary perspective. 


\section{Study 1a: Method}

\section{Sample and Procedures}

We recruited 70 participants who self-identified as employed adults who were currently working in workgroups using Amazon’s Mechanical Turk. Among these participants, 45\% selfidentified as women, and the average age of the sample was 29 (SD = 10.32). The study adopted a between-subjects design in which we first manipulated workgroup conflict and then assessed resource depletion. The University of British Columbia’s IRB granted approval for Studies 1a and $1 \mathrm{~b}$ under the Squeezing a handgrip, resource depletion, and team performances application, study number: H12-01039.

\section{Experimental Manipulations}

Workgroup conflict was manipulated by utilizing a salience induction method (e.g., Wichman, Brunner, \& Weary, 2008). Participants were randomly assigned a condition and asked to provide detail in writing of a time when they either encountered a workgroup experience with conflict or a workgroup experience with minimal conflict. We reasoned, based on social cognitive principles (Higgins, 1996), that bringing a conflict to the mind of participants would also activate associated knowledge structures about what the consequences of the conflict might have been. It has been shown that simply ruminating on past conflict events can bring back thoughts and feelings associated with that conflict, which could potentially elicit resource depletion (Bushman, 2002; Denson, 2009). In other words, employees do not necessarily have to be in the midst of experiencing conflict for it to be resource depleting. It is possible that simply thinking about conflict and its negative associations can result in some level of depletion, albeit not as much as when one is actually dealing with conflict. 
Participants were first given descriptions about low or high workgroup conflict experiences, depending on the assigned conditions, and they were asked to recall their own experience about those given conditions. Low workgroup conflict experiences were described to participants as follows: typically occurring when relationship tension is not present among workgroup members; members are generally satisfied with one another, interacting in a positive manner, and, at times, expressing their happiness with one another; and workgroup members have very little conflict of ideas or disagreement about tasks, sharing similar opinions about assignments. High workgroup conflict experiences were described to participants as follows: typically occurring when relationship tension is present among workgroup members; emotional conflict can exist among the members, facilitating them to get angry or upset while working; and workgroup members have disagreements about tasks with conflicting ideas and opinions regarding assignments. Participants were asked to think about the workgroup interaction for a couple of minutes, imagining the thoughts, actions, and feelings they experienced. Then, depending on condition, they were asked to write a detailed description of either the low conflict or high conflict encounter.

\section{Measures}

Resource Depletion. We measured resource depletion using Sasaki and Vorauer’s (2010) six item scale, which includes statements such as “I feel mentally exhausted” and "My mental energy is running low.” Participants indicated their agreement to how they were feeling at the current moment on a 7-point Likert scale, and their answers were averaged to create a resource depletion score with a higher score indicating a higher level of resource depletion $(\alpha=$ $.94)$.

\section{Study 1a: Result and Discussion}


Supporting our claim, results revealed that participants from the high conflict condition reported a higher level of resource depletion $(\mathrm{M}=3.89, \mathrm{SD}=1.22)$ than their counterparts from the low conflict condition $(\mathrm{M}=3.01, \mathrm{SD}=1.55), \mathrm{F}(1,66)=5.47, \mathrm{p}<.05$. Having demonstrated the depleting effect of workgroup conflict on resources, we now proceed to Study 1b in which we experimentally test the effect of victimization severity on forgiveness as well as the moderating role of workgroup conflict on the victimization-forgiveness relationship.

\section{Study 1b: Method}

\section{Sample and Procedures}

The sample consisted of elementary and secondary school teachers recruited from multiple sources to complete an online experiment. We selected elementary and secondary school teachers because they not only work in environments where their clients (i.e., students) commonly bully one another but also they can be targeted by these same clients at disconcerting rates (Sinclair, Martin, \& Croll, 2002; Terry, 1998). School teachers were contacted via email and social media outlets by one of the authors. Along with being asked to participate in the study, these teachers were also asked to forward the study invitation to their teaching colleagues in their respective schools and school districts. Additionally, we selected the state of Mississippi to further recruit elementary and secondary educators. Through the State of Mississippi Department of Education’s website (www.mde.k12.ms.us), 152 public school districts were identified. We then navigated to the website of each of the school districts, identified the administrator email contact for each school in the 152 districts, and emailed the administrators regarding the on-line experiment, requesting that they forward the study invitation to their respective school's faculty. Occasionally, schools and their districts list the names and emails of their teaching faculty. If this was made available, we also emailed the teacher directly. From 
these two efforts, 575 school teachers clicked on the study link that was provided in the study invitation, indicating their interest in being a participant. Of these 575 interested teachers, 254 decided to continue as study participants (44.2\% of those indicating interest) and 225 actually completed the study in its entirety (88.6\% of the 254 ; $39.1 \%$ of the 575$) .84 .2 \%$ of our teacher participants were female, and $13.6 \%$ identified as a minority. Participants’ average age was 43.1 years ( $S D=11.57)$, and their average tenure as a teacher was 14.8 years ( $S D=9.94)$.

The online experiment used a $2 \times 3$ between-subjects design. We manipulated workgroup conflict (high vs. low workgroup conflict) and victimization severity (high vs. medium vs. low victimization severity). Teachers were randomly assigned to one of 6 experimental conditions.

\section{Experimental manipulations}

Victimization severity manipulation. To manipulate victimization severity, we adapted Lanza and Carifio’s (1990) client aggression vignettes. The scenario asked participants to imagine that they are having a casual conversation with Taylor, to whom they provide instruction. Communication breaks down between the participant and Taylor, and Taylor instigates aggression toward the participant. In the low victimization severity condition, the scenario explains that Taylor swears, telling the participant what s/he "can do" and where s/he “can go.” These phrases are colloquial euphemisms for swearing that would be understood by participants. Taylor then abruptly walks away, ending the vignette.

In the medium victimization severity condition, Taylor swears, telling the participant what s/he "can do" and where s/he "can go,” and further grabs the participant firmly by the wrist. The participant requires assistance to get free from Taylor's grasp and is left with a reddened mark on the wrist after the incident, ending the vignette. 
In the high victimization severity condition, Taylor swears, telling the participant what s/he "can do" and where s/he "can go," and further grabs the participant firmly by the wrist and punches her/him on the arm. The participant loses her/his balance, falls, and hits her/his head against the wall. As assistance arrives, the participant realizes s/he is bleeding from several head abrasions and has a badly sprained arm and wrist, ending the vignette.

A manipulation check embedded in the experiment provided evidence of increasing victimization severity across the three conditions. A one-way ANOVA revealed that the three conditions were significantly different across conditions $(\mathrm{F}(2,230)=52.83, p<.001)$. Pairwise comparison of the means across the three conditions suggested that the mean difference between low and medium victimization severity was significant $((\mathrm{M}=3.01, \mathrm{SD}=1.15$ vs. $\mathrm{M}=3.62, \mathrm{SD}$ $=1.50), \mathrm{t}(153)=-2.83, p<.01)$. The mean difference between low and high victimization severity was also significant $((M=3.01, \mathrm{SD}=1.15$ vs. $\mathrm{M}=5.22, \mathrm{SD}=1.49), \mathrm{t}(155)=-10.39$, $\mathrm{p}<.001)$. Finally, the difference in means between medium and high victimization severity was significant $((\mathrm{M}=3.62, \mathrm{SD}=1.50$ vs. $\mathrm{M}=5.22, \mathrm{SD}=1.49), \mathrm{t}(152)=-6.64, p<.001)$.

After reading the randomly assigned victimization severity manipulation vignette, participants were presented with the forgiveness scale. They then completed a demographic questionnaire at the end of the experiment. The mean of the manipulated victimization severity score was 2.11 ( $\mathrm{SD}=0.81$ ). Low severity was coded as 1 , medium severity as 2 , and high severity as 3. Victimization severity's correlation with forgiveness was $-0.01(\mathrm{p}>.10)$ and with workgroup conflict was $0.04(\mathrm{p}>.10)$.

Workgroup conflict. Workgroup conflict was manipulated as in Study 1a. In this current study, the conflict manipulation occurred prior to the victimization manipulation. The mean of 
the manipulated workgroup conflict score was $0.50(\mathrm{SD}=0.50)$. Workgroup conflict's correlation with forgiveness was $-0.13(p=.07)$ and with victimization severity was $0.04(p>.10)$.

The effectiveness of the manipulation was assessed by asking participants to indicate how much conflict was present in the workgroup interaction that they described on a seven-point Likert (1-no conflict at all to 7-a lot of conflict). A one-way ANOVA indicated that the two workgroup conflict conditions were significantly different from each other $F(1,226)=85.29, p<$ .001. As expected, the mean for participants assigned high conflict condition was 3.72 ( $\mathrm{SD}=1.79)$ compared to $1.79(\mathrm{SD}=1.35)$ in the low conflict condition.

\section{Measures}

Forgiveness. Three items were used to measure forgiveness. Two items are from Aquino et al.’s (2006) original four items: “I let go of the negative feelings I had against the instigator,” and "I let go of the resentment I felt toward the instigator." The other two items (i.e., "I let go of my hate and desire for vengeance,” and “I let go of my hurt and pain”) did not appear appropriate for our sample given the nature of teachers’ work tasks and interactions with students. Hence, we modified these items to a more general item: "I forgave Taylor for what Taylor did to me.” Items were preceded by the prompt, “After I experienced this interaction with Taylor...”. Participants were instructed to select the response that best represented the accuracy of what they would do after the act of aggression described in the vignette took place, on a seven-point Likert scale ( $1-$ Not at all accurate to 7 -Very accurate; $\alpha=.88$ ). The mean score was 4.55 ( $\mathrm{SD}=1.57)$. In addition to the three forgiveness statements, participants also responded to several distractor statements that reflected other coping strategies (i.e., avoidance and revenge) such as "I try to keep as much distance from Taylor as possible,” and "I think Taylor should 
receive punishment for what happened," and Cronbach’s alpha for these scales were .72 and .71, respectively.

\section{Study 1b: Results}

\section{Hypothesis Testing}

Thirty participants were excluded from analysis because they did not identify themselves as currently working in a workgroup or did not complete the high/low workgroup conflict exercise (i.e., the text box was left blank). We note that results remain the same with or without these participants. Excluding these 30 participants left 27 participants in the low conflict and low severity condition, 39 in the low conflict and medium severity condition, 35 in the low conflict and high severity condition, 29 in the high conflict and low severity condition, 30 in the high conflict and medium severity conflict, and 43 in the high conflict and high severity condition. We tested for systematic difference in participant demographics across these 6 randomly assigned conditions and found no difference.

Hypothesis 1 predicted an inverted-U shape relationship between victimization severity and forgiveness, such that forgiveness increases as victimization severity increases until victimization becomes too severe to forgive, at which point forgiveness will start to decrease. We tested this hypothesis by comparing forgiveness in the high, medium, and low severity conditions. Results of a $2 \times 3$ between-subjects ANOVA revealed a significant main effect of victimization severity (see Table 1 ), $\mathrm{F}(2,189)=3.98, p<.05$. Consistent with Hypothesis 1 , pairwise comparison suggested that forgiveness was higher in the medium severity condition than in the low $(\mathrm{M}=5.02, \mathrm{SD}=1.43$ vs. $\mathrm{M}=4.28, \mathrm{SD}=1.55, \mathrm{t}(117)=2.73, p<.01)$ and in the high severity condition $(\mathrm{M}=5.02, \mathrm{SD}=1.43$ vs. $\mathrm{M}=4.32, \mathrm{SD}=1.63, \mathrm{t}(141)=2.73, p<.01)$, suggesting an inverted U-shape relationship between victimization severity and forgiveness. 
Table 2 provides a summary of means for forgiveness while Figure 2 provides a depiction of this overall relationship across victimization severity levels.

Insert Tables 1-2 and Figure 2 about here

Hypothesis 2 predicted that workgroup conflict would moderate the inverted-U shape relationship between victimization severity and forgiveness such that the relationship is more likely in the presence of low, rather than high, workgroup conflict. Supporting Hypothesis 2, results of the $2 \times 3$ ANOVA (presented in Table 1 ) revealed a significant two-way interaction between the workgroup conflict manipulation and the victimization severity manipulation $(\mathrm{F}(2,189)=3.64, p<.05)$. Decomposition of this interaction by workgroup conflict revealed an inverted-U shape relationship between victimization and forgiveness in the low, rather than high, workgroup conflict condition: when workgroup conflict was low, forgiveness was higher in the medium severity condition than in the low $(M=5.53$, $S D=1.26$ vs. $M=4.28, S D=1.56, t(61)$ $=3.50, p<.001)$ and in the high $(\mathrm{M}=5.53, \mathrm{SD}=1.26$ vs. $\mathrm{M}=4.25, \mathrm{SD}=1.45, \mathrm{t}(71)=4.02, p<$ .001) severity conditions. When workgroup conflict was high, forgiveness did not differ significantly between the medium and the low $(\mathrm{M}=4.37, \mathrm{SD}=1.39$ vs. $\mathrm{M}=4.27, \mathrm{SD}=1.57$, $\mathrm{t}(54)=.24$, n.s. $)$ as well as the medium and the high $(\mathrm{M}=4.37, \mathrm{SD}=1.39$ vs. $\mathrm{M}=4.38, \mathrm{SD}=$ $1.78, \mathrm{t}(68)=.04$, n.s.) severity conditions. Table 2 also summarizes means for forgiveness in each experimental condition respectively, while Figure 2 also graphically presents these means.

\section{Additional Analyses}

To test how victimization and workgroup conflict predict maladaptive coping responses and to compare these effects with those on forgiveness, we also examined the effects of victimization severity and conflict manipulations on revenge and avoidance. A 2x3 ANOVA 
revealed nonsignificant main effects for victimization $(F(2,186)=.55$, $p=n . s$.$) and workgroup$ conflict $(F(1,186)=.19, p=n . s$.$) manipulations on revenge and a nonsignificant effect for their$ interaction $(\mathrm{F}(2,186)=.37, \mathrm{p}=\mathrm{n} . \mathrm{s}$.$) on revenge. In addition, the results also revealed$ nonsignificant main effects for victimization $(F(2,186)=1.58, p=n . s$.$) and conflict (F(1$, 186) $=.20$, $\mathrm{p}=\mathrm{n} . \mathrm{s}$.) manipulations on avoidance and nonsignificant effect for their interaction on avoidance $(\mathrm{F}(2,186)=1.20, \mathrm{p}=\mathrm{n} . \mathrm{s}$.$) . We attribute this result to our sample as revenge and$ avoidance can jeopardize human service workers' occupational code of conduct and likely place their job at risk.

\section{Study 1b: Discussion}

Our results supported Hypotheses 1 and 2. The evidence demonstrates that victimization severity was more predictive of forgiveness particularly when workgroup conflict was low rather than high. Forgiveness was more likely in the medium than in the low or high severity conditions, and this pattern prevailed under conditions of low workgroup conflict. This is likely because there was no strong basis for forgivingness at low victimization levels, and at severe levels, the threshold was so high that even employees with ample resources would find it difficult to forgive. When workgroup conflict was high, it was likely that employees' resources had already been depleted from having to manage conflict and, thus, lacked adequate resources to forgive abusive clients.

\section{Study 2}

Study 2 was conducted to test all our hypotheses and to replicate findings of Study $1 \mathrm{~b}$ in an actual workplace context. In order to triangulate and corroborate our results across studies (Mathison, 1988; Webb, Campbell, Schwartz, \& Sechrest, 1966), we measured victimization frequency in Study 2, rather than severity. Previous research on workplace aggression 
demonstrates that severity and frequency are not unrelated (e.g., Magley, Hulin, Fitzgerald, \& DeNardo, 1999; O'Leary-Kelly, Bowes-Sperry, Bates, \& Lean, 2009; Sinclair et al., 2002). In fact, Sinclair et al. (2002) investigated physical and psychological aggression of students toward teachers, and found that, while physical (more severe) aggression was experienced less frequently than psychological (less severe) aggression, both forms had similar consequences. Other evidence suggests that severe and less severe aggression co-occur (O’Leary-Kelly et al., 2009); hence, when victims are experiencing more severe forms, they also are simultaneously experiencing less severe, higher frequency aggression (i.e., "severity contains an element of frequency;” O’Leary-Kelly et al., 2009, p. 7; Magley et al., 1999). Given that these different measures led to similar conclusions, particularly with the curvilinear findings between victimization and forgiveness, we can have more confidence in the interpretation of these results and their robustness (see Webb et al., 1966).

\section{Study 2: Method}

\section{Participants and Procedure}

Participants were Midwestern US unionized direct-care nursing employees from 28 metropolitan and suburban long-term care (LTC) facilities. In a series of focus group interviews, nursing employees reported experiencing behaviors such as yelling, swearing, insults, hitting, grabbing, spitting, biting, having objects thrown at them, and other physical threats instigated by their patients. This knowledge informed our survey instrument design. Surveys were distributed to 1,636 unionized nursing employees through their union organization, and 318 responses were obtained (19.4\% overall response rate; 20.3\% average facility response rate). Of these, 11 incomplete surveys were eliminated. Response rates from unionized samples typically are not high, and our overall response rate reflects those of other union attitudinal studies (e.g., 
Kelloway, Catano, \& Southwell, 1992, 17.2\%; Twigg, Fuller, \& Hester, 2008, 16\%).

Classifying the nursing respondents in their appropriate workgroups nested 281 respondents in 53 workgroups with workgroups ranging in size from 2 to 18 respondents $(\mathrm{M}=$ $5.3 ; \mathrm{SD}=3.8$ ) and group response rates ranging from $17 \%$ to $100 \%$. Members in workgroups worked together during the same shift and interacted at least daily, if not hourly. Seventy-nine percent of the workgroups had 3 or more employees (i.e., 42 out of 53 workgroups). Groups of two were kept within the sample because LTC facilities limit their staff to two employees during late shifts while patients are sleeping. To assuage concerns linked to workgroups with very low response rates (cf. Schneider, Ehrhart, Mayer, Saltz, \& Niles-Jolly, 2005), we conducted separate analyses that omitted workgroups having less than a 25\% response rate. The reduced sample analyses replicated our full sample analyses, and the analyses were not significantly different from each other - suggesting that very low group response rates did not bias our study's results.

We dropped 59 participants who had average victimization scores of 1 (not at all), which meant that they had not been victimized and, therefore, would be unable to assess forgiveness as a coping mechanism because they had nothing to forgive (e.g., Wasti \& Cortina, 2002). By dropping participants with missing data, with no identified workgroup, and with average victimization scores of 1, our final sample size was 213 (92\% female; 89\% non-minority). ${ }^{1}$ Average age was $41.70(\mathrm{SD}=13.91)$, and average tenure 8.88 years $(\mathrm{SD}=9.16)$. Our respondents were not significantly different from their sample population for gender $(t(1847)=$ $.53, p=.60)$, race $(t(1847)=.84, p=.40)$, or age $(t(1847)=1.56, p=.12)$. The University of Minnesota’s IRB granted approval for Study 2 under the Securing nursing and patient safety

\footnotetext{
${ }^{1}$ To assuage any concern regarding dropping observations from analyses and potential range of restriction issues, we conducted additional analyses using the full sample which includes the employees with victimization score of 1 . The results are presented in Tables A and B in the Appendix. As the tables show, the results were largely consistent with the results obtained from the sample which excludes those employees with victimization score of 1 .
} 
initiative application, study number: 0512P78628.

\section{Measures}

Victimization. The direct-care nursing employees were presented 17 victimization items and asked how often they were victimized by their patients in the past six months. We used Aquino, Grover, Bradfield, and Allen’s (1999) 14-item workplace victimization scale as the foundation for victimization items. Among the original 14 items, we reworded "Made a racial or religious slur” to make it more general: “Insulted, criticized me.” Two items were dropped to reflect the sample characteristics: "Stole my possessions" because of the low base rate and "Refused to talk to me" because direct-caregivers had difficulty distinguishing this behavior as a form of victimization or a patient's inability to communicate. Following focus group interviews, we added four items from Glomb and Liao (2003) and one item from Rogers and Kelloway (1997) to ensure that the gamut of negative patient behaviors that caregivers encounter was represented in the instrument. Example items are as follows: did something to make me look bad; sabotaged my work; yelled or raised their voice at me; pushed or punched me; threw something at me. The items had seven response options from 1 (never) to 7 (daily). The 17 items were averaged to create the individual score $(\alpha=.93)$.

Workgroup Conflict. Respondents were asked to what extent conflict occurs in their workgroup. Six items from Jehn and Mannix’s (2001; cf. Jehn, 1995) intragroup conflict scale were used to measure workgroup conflict: three items for relationship conflict and three items for task conflict (e.g., "How much relationship tension is there in your workgroup?”). The items had five response options from 1 (none) to 5 (a lot) $(\alpha=.92)$.

The correlation between task and relationship conflict in the current study was .84 (consistent with previous studies measuring the two conflict types in health care samples: $r=.67$ 
in Friedman, Tidd, Currall, \& Tsai, 2000; and $r=.84$ in Han \& Harms, 2010). The size of the correlation suggested that the two conflict types were not distinct. In addition, a confirmatory factor analysis (CFA) indicated that the two-factor model $\left(\chi^{2}(5,307)=10.402\right.$, CFI=.996, RMSEA $=.059)$ did not fit the data better than a one-factor model $\left(\chi^{2}(6,307)=11.989\right.$, CFI $=.996$, RMSEA=.057), and the chi-square difference test revealed no significant difference between the two models and showed that the single factor model was sufficient $\left(\Delta \chi^{2}(1,307)=1.587\right.$, n.s. $)$. We tested our model using the combined, six-item one-factor measure, as well as using either the task conflict or relationship conflict measure in separate analyses. The findings were consistent for all analyses, so we deemed it appropriate to combine the task and relationship conflict items into a single measure of workgroup conflict.

We conceptualized workgroup conflict as a group level construct. Thus, we calculated scores at the group level by aggregating the individual scores to the group mean for each workgroup. To justify aggregation, we assessed between-group variance in relationship to total variance (ICC[1]) and group mean reliability (ICC[2]; Kozlowski \& Klein, 2000). The ICC Fstatistic was significant $(p<.001, F(52,228)=1.96)$, indicating significant between-group differences for workgroup conflict. The ICC[1] value of .15 from our sample surpassed the average ICC[1] level attained in organizational research (i.e., .12, James, 1982; Ostroff \& Schmitt, 1993). The ICC[2] from our sample was .49. The recommended ICC[2] threshold is .60 (Glick, 1985; Ostroff \& Schmitt, 1993). Though our ICC[2] value is slightly below the suggested value, it is a moderate value for this statistic, and scholars have indicated the appropriateness for aggregation at these moderate levels (Schneider, White, \& Paul, 1998). We further determined within-group agreement, $\mathrm{r}_{\mathrm{wg}(\mathrm{j})}$, across the groups (James, Demaree, \& Wolf, 1993). The workgroup conflict $r_{\mathrm{wg}(\text { ) }}$ group average was .67 (median $=.79$ ) with $76 \%$ of groups at or above 
.60. (i.e., .60 is the suggested cutoff, James, 1982). These results support the appropriateness of aggregating individual conflict scores to obtain a group-level measure.

Forgiveness. Forgiveness was measured using the three items from Study $1 \mathrm{~b}$.

Participants were asked to indicate how accurately each statement described what they did after experiencing aggression from their patients in the past six months. The items had five response options ranging from 1 (Not at all accurate) to 5 (Very accurate) $(\alpha=.93)$.

Turnover Intentions. Rogers and Kelloway’s (1997) two-item scale was used to measure intentions to leave. The two items, using a five-point Likert $(1=$ Strongly Disagree, 5 = Strongly Agree), are "I will probably look for a new job outside of my current workplace in the next year”; "I will probably look for a new occupation in the next year.” The Spearman-Brown for the two items was .77.

Emotional Burnout. We used Iverson, Olekalns, and Erwin’s (1998) three-item emotional burnout scale (e.g., “I feel emotionally drained from work”) with a five-point Likert response scale ranging from $1=$ Strongly Disagree to $5=$ Strongly Agree $(\alpha=.91)$.

Job Satisfaction. We used one item from Cammann, Fichman, Jenkins, and Klesh (1983): “All in all, I am satisfied with my job” (1 = Strongly Disagree, 5 = Strongly Agree $)$ following Wanous, Reichers, and Hudy's (1997) suggestion that a one-item job satisfaction measure is as effective as a multi-item job satisfaction scale.

Control variables. We controlled for seven variables that may be theoretically related to victimization, forgiveness, and workplace attitudes. Employees' Age and Tenure were controlled because direct-care nursing employees with more life and on-the-job experience may manage patients' aggressive acts differently than those who are younger or new to the field or organization. Level of Education was also controlled because educational experience and 
training may influence the responses of individuals reporting victimization, as well as signal their status in the organization ( 1 = Less than high school to $7=$ Advanced degree $)$. Neuroticism was controlled because more neurotic individuals may be more likely to recall and report negative incidents (cf. Blaney, 1986) and less likely to engage in forgiveness (Fehr et al., 2010). Agreeableness was controlled because agreeable individuals are more likely to engage in forgiveness (Strelan, 2007). Gosling, Rentfrow, and Swann’s (2003) two-item neuroticism and two-item agreeableness measures from their ten-item Big-Five personality inventory were used with a five-point Likert scale $(1=$ Strongly Disagree, 5 = Strongly Agree $)$. An example item for neuroticism is "I am anxious and easily upset," and for agreeableness is "I am sympathetic and warm.” The Spearman-Brown reliability was .52 for neuroticism and .50 for agreeableness. Care for those who have neurological or psychological disabilities, labeled as Care for disabilities, was controlled because caregivers working with such patients may report more victimization. Participants reported the percentage of time that they worked with neurologically and/or psychologically disabled patients based on the scale $(1=0-20 \%$ to $5=80-100 \%)$. Finally, workgroup shift size was measured as the number of employees working together during the same shift, and it was controlled because the unit size may relate to within-unit interaction patterns as well as individual outcomes (Duffy, Ganster, Shaw, Johnson, \& Pagon, 2006). Analyses were conducted with and without control variables, and, comparing the two, results were consistent and robust.

\section{Analytical Approach}

The data in the present study were multilevel, with workgroup conflict at the group level and victimization, forgiveness, and workplace attitudes at the individual level. We therefore used hierarchical linear modeling (HLM; Bryk \& Raudenbush, 1992) to test our cross-level 
hypotheses. Our analysis involved a cross-level interaction. Thus, we group-mean centered the victimization variable and grand-mean centered the workgroup conflict variable. This way, the reported parameter estimates show only the within-group effect, parsing out the between-group effect (Aguinis, Gottfredson, \& Culpepper, 2013; Enders \& Tofighi, 2007). In addition, we tested the model fit by deriving $\mathrm{R}^{2}$, computed as the square of the correlation between the observed outcome and fixed-effect predicted outcome (Hoffman, 2015).

\section{Study 2: Results}

The descriptive statistics and correlations among the study variables are presented in Table 3. Table 4 presents the HLM results when forgiveness was used as the dependent variable. Model 3 shows that the squared victimization variable was significant $(\gamma=-.13, p<.01)$. As shown in Figure 3, there was an inverted-U shaped relationship between victimization and forgiveness, supporting Hypothesis 1.

Insert Tables 3-4 and Figures 3-4 about here

Testing the moderation of a curvilinear effect is akin to testing a three-way interaction, requiring all possible combinations of the component variables to be included in the model (Cohen, Cohen, West, \& Aiken, 2003). In Model 2, the interaction of the squared victimization term and workgroup conflict was significant $(\gamma=.30, p<.05)$. The form of the plot, illustrated in Figure 4, shows that the inverted-U shaped relationship between victimization and forgiveness appears only when workgroup conflict is low. Simple slope tests revealed that when workgroup conflict was low, both linear $\left(\gamma_{\text {linear victimization under low conflict }}=.44, p<.01\right)$ and the squared victimization terms $\left(\gamma_{\text {squared victimization under low conflict }}=-.12, p<.01\right)$ were significant, but neither the linear $\left(\gamma_{\text {linear victimization under high conflict }}=-.04\right.$, n.s. $)$ nor the squared $\left(\gamma_{\text {squared victimization under high Conflict }}\right.$ 
Squared $=-.05$, n.s.) simple slopes were significant when workgroup conflict was high. In Figure 4, it appears that at the lower level of victimization, high workgroup conflict employees were more forgiving than low workgroup conflict employees. Therefore, we conducted simple slope tests to examine whether the forgiveness level was significantly different across workgroup conflict levels when victimization was at this low level. Results showed that the forgiveness level was not different across workgroup conflict levels when victimization was low $\left(\gamma_{\text {Low Victimization }}=.25\right.$, n.s.), but was significantly different when victimization was high $\left(\gamma_{\text {High Victimization }}=-.71, p<.05\right)$. Hence, Hypothesis 2 was supported.

Models 3 to 5 in Table 4 presents HLM estimates of the predictors of the workplace outcome variables (i.e., job satisfaction, burnout, turnover intentions). The results show that the mediating variable - forgiveness - was significantly related to job satisfaction $(\gamma=.15, p<.05$, Model 3), burnout $(\gamma=-.16, p<.05$, Model 4), and turnover intentions $(\gamma=-.12, p<.05$, Model 5). To test Hypothesis 3, we took the nested-equation path analytic approach to moderated mediation from Edwards and Lambert (2007) based on the HLM estimates from Table 4. In this process, we constructed confidence intervals for the significance tests by estimating the sampling distributions of the product of regression coefficients using a bootstrap procedure with 20,000 replications (MacKinnon, Fairchild, \& Fritz, 2007; Selig \& Preacher, 2008).

The path analytic results are shown in Table 5, where Pмx is the path from X (victimization) to $\mathrm{M}$ (forgiveness), $\mathrm{PMX}^{2}$ is the path from $\mathrm{X}^{2}$ (squared victimization) to $\mathrm{M}$ (forgiveness), PyM is the path from M (forgiveness) to $\mathrm{Y}$ (workplace outcomes), Pyx is the path from $\mathrm{X}$ to $\mathrm{Y}$ (that is, the direct effect of victimization on workplace outcomes), РумРмx is the indirect linear effect, and РүмРмх² is the indirect curvilinear effect. Table 5 shows that the indirect effects of victimization on workplace outcomes, through forgiveness, vary across levels 
of workgroup conflict. When workgroup conflict was low, the indirect curvilinear effects of victimization on workplace outcomes through forgiveness were significant: job satisfaction $\left(\mathrm{P}_{\mathrm{YM}} \mathrm{P}_{\mathrm{MX}}{ }^{2}=-.06, p<.05\right)$, burnout $\left(\mathrm{P}_{\mathrm{YM}} \mathrm{P}_{\mathrm{MX}}{ }^{2}=.07, p<.05\right)$, and turnover intention $\left(\mathrm{P}_{\mathrm{YM}} \mathrm{P}_{\mathrm{MX}}{ }^{2}=\right.$ $.05, p<.05)$. However, when workgroup conflict is high, forgiveness does not mediate the indirect curvilinear effects of victimization on the three workplace outcome variables: job satisfaction $\left(\mathrm{P}_{\mathrm{YM}} \mathrm{P}_{\mathrm{MX}}{ }^{2}=-.01\right.$, n.s. $)$, burnout $\left(\mathrm{P}_{\mathrm{YM}} \mathrm{P}_{\mathrm{MX}}{ }^{2}=.01\right.$, n.s. $)$, and turnover intent $\left(\mathrm{P}_{\mathrm{YM}} \mathrm{P}_{\mathrm{MX}}{ }^{2}=\right.$ .01 , n.s.).

Insert Table 5 and Figure 5-7 about here

Figures 5, 6, and 7 illustrate the total effects of victimization on workplace outcomes through forgiveness at low and high workgroup conflict levels. Figure 5 shows that when workgroup conflict is low, the indirect effect of victimization on job satisfaction through forgiveness is inverted-U shaped. However, when workgroup conflict is high, forgiveness does not significantly mediate between victimization and job satisfaction, as results in the top panel of Table 5 indicate. Without forgiveness mediating, the graph of the total effect between victimization and job satisfaction, under high workgroup conflict, is negative. Contrasting the total effects under low and high workgroup conflict, the total effect, under low workgroup conflict, is positive from low to moderate victimization levels, yet becomes negative at higher victimization levels, similar to the total effect under high workgroup conflict.

Figure 6 shows that when workgroup conflict is low, the indirect effect between victimization and burnout through forgiveness takes a positive curvilinear form. When workgroup conflict is high, forgiveness does not mediate the victimization and burnout relationship (as shown in the mid-panel in Table 5), and the graph of the total effect shows a 
positive linear relationship. Under conditions of low workgroup conflict, the positive total effect is attenuated, especially for low to moderate victimization levels, as compared to the high workgroup conflict condition.

Lastly, Figure 7 illustrates that under low workgroup conflict, the indirect relationship between victimization and turnover intentions through forgiveness takes a negative curvilinear form; turnover intentions decline for low to moderate victimization levels but begin to plateau at more egregious levels. Under high workgroup conflict, forgiveness does not mediate (see bottom panel of Table 5), and the graph shows there is no systematic relationship between victimization and turnover intentions. Hypothesis 3 was supported for the three workplace outcomes.

\section{Study 2: Discussion}

Overall, Study 2 supported our prediction that the relationship between client-instigated victimization and forgiveness would take an inverted curvilinear form - particularly for individuals in low conflict workgroups. It also supported our prediction that forgiveness mediates the indirect relationship between client-instigated victimization and three workplace outcomes, under low workgroup conflict conditions. Further, Study 2 has several strengths that include (1) a sample drawn from a real organization where the employees are human service employees who work together interdependently to deliver care to their clients with whom they have ongoing relationships; (2) a large sample size; and (3) replication of the cross-level moderated mediation model across three different workplace outcomes. Although Study 2 allowed us to extend our curvilinear model to workplace outcomes, the cross-sectional design only allows us to investigate between-person effects, at one point in time, and prevents us from making causal inferences. To address these concerns, we conducted a constructive replication of Study 2 using a daily diary study. Using a daily diary study, we are able to extend our curvilinear 
model to workplace outcomes as in Study 2, yet, with this design, we are also able to look at our questions longitudinally and understand how much individuals in our sample tend to change over time (i.e., within-person effects). Additionally, as a constructive replication, Study 3 extends the generalizability of the previous research by not exactly duplicating the previous methods (Lykken, 1968). We use a service employee sample outside of human service work. If consistent patterns are determined across our studies, then we should have greater confidence in our previously obtained findings and in the potential for our theorizing to be extended to service populations other than human services.

\section{Study 3: Method}

\section{Participants and Procedure}

Ninety-four service employees who had direct interaction with clients on a daily basis (i.e., branch customer service agents, meter readers, and technicians), working in seven different branches of a utility provider in the Jiangsu Province, China, were recruited. Paper-based survey data collection occurred in three waves. In the first wave, we collected demographic information and workgroup conflict perceptions from participants. In the second wave, which began one week following the end of the first wave, we collected a ten-day diary study capturing daily client-instigated victimization, daily coping responses to victimization, and daily employee workplace attitudes. One week following the completion of the diary study, we started wave 3 which captured employee personality variables. There were twelve surveys in total across the three waves that participants were asked to complete. We adhered to Brislin's (1970) translation and back translation technique to ensure that items were appropriately translated and understood by our participants.

Across the three waves of data collection, all 94 participants responded to all twelve 
surveys. Participants placed each of their respective surveys in its designated self-sealed envelope, and when completed, envelopes were immediately collected by a member of the research team. Our response rate was high for several reasons. First, one of the authors has an established relationship with the organization's management team. Second, the research team conducted sessions to train managers on the study's purpose, its benefits to the organization and employees, and the confidentiality and anonymity of the surveys. Third, the research team personally met with the participants and also provided personal discussion and materials that described the above and the importance of their participation. These efforts helped to attain buyin throughout the hierarchy.

Of the 94 participants, 80 participants provided complete data across the three waves ( $85.1 \%$ of the participants), of whom $18.7 \%$ were women, the average age was 43.04 years $(\mathrm{SD}=8.25)$, and the average tenure with the organization was 16.90 years $(\mathrm{SD}=7.57)$. Of these, 8 employee-level observations were dropped because of suspect responses (e.g., indicated the same response across items) and 8 employee-level observations were dropped because they reported that they were not victimized, and, thus, would not be able to assess forgiveness as a coping mechanism as they had nothing to forgive. ${ }^{2}$ Study 3 was conducted in compliance with the London School of Economics’ research ethics policy and guidelines.

\section{Measures}

Study 3 used scales and items also used in Study 2.

Victimization. In the daily diary study, participants were instructed to think of the negative client interactions that they were exposed to on the given day. Similar to Study 2, Aquino et al.’s (1999) 14-item scale was used. After speaking to the utility's management about incidents employees experience to discern appropriate items, it was decided to drop the item,

\footnotetext{
${ }^{2}$ See the Appendix for analyses with the full sample.
} 
stole my possessions, because of the low likelihood of customers having access to employees’ personal possessions. Additionally, as in Study 2, we complemented the above scale with four items from Glomb and Liao (2003). However, unlike Study 2, we did not use the item "bit me" from Rogers \& Kelloway (1997) in Study 3 because the item was inappropriate for the current sample. On each day, participants indicated for each of the 17 items how frequently they encountered the specific client-instigated behavior on that day, using a seven-point (1=Never to 7=All of the time $)$ Likert response scale $(\alpha=.93)$.

Workgroup Conflict. In the first wave of data collection, participants were asked to indicate across six items their individual perceptions of how much conflict occurs among coworkers with whom they directly work, on a seven-point (1=Not at all to $7=A$ lot $)$ Likert response scale $(\alpha=.84)$.

Forgiveness. Each day of the diary study, participants were asked to think about the negative client interactions that they had indicated as experiencing that specific day and to choose the response that best represents how accurate the three items were to them, on a sevenpoint Likert (1=Not at all accurate to 7=Very accurate) Likert response scale $(\alpha=.97)$.

Workplace Outcomes. In the daily diary, participants were asked to think about their day at work and to indicate their level of agreement for each of the items based on their thoughts and emotions on that particular day. In effort to increase variation in response, we used a sixpoint scale (1=Strongly disagree to 6=Strongly agree), as suggested by Si and Cullen (1998). East Asian participants may have a tendency to select the midpoint, neutral category (i.e., neither agree nor disagree) in an odd-numbered agreement scale (Si \& Cullen, 1998). The alphas for our dependent variables are as follows: turnover intentions, $\alpha=.84$ and emotional burnout, $\alpha=.87$. As in Study 2, we used a one-item, global job satisfaction measure (Wanous et al., 1997). 
Control variables. Similar to Study 2, we controlled for employees’age, tenure, level of education, neuroticism $(\alpha=.50)$, and agreeableness $(\alpha=.69)$. We used a six-point scale for neuroticism and agreeableness given the same above reasons (1=Strongly disagree to 6=Strongly agree). Additionally, we controlled for revenge coping. Using the same anchors as the forgiveness scale, we captured revenge coping behavior each day of the diary study with three items from Bradfield and Aquino (1999), e.g., "I got even with them;” "I did something to make them pay," $\alpha=$.73. Given that forgiveness requires the transformation of negative emotions to more positive ones, we wanted to ensure our effects would hold over and above revenge. Engaging in revenge indicates that the victim has negative thoughts about the perpetrator, which “creates a cognitive barrier to the consideration of forgiveness strategies” (Bradfield \& Aquino, 1999, p. 611). Analyses were conducted with and without control variables, and, comparing the two analyses, results were consistent and robust.

\section{Analytical Approach}

We used HLM because the Study 3 data were multilevel in that the same individual level variables were measured across 10 waves; thus within-individual level observations were nested within between-individual level. As in Study 2, we group-mean centered the victimization variable and grand mean centered the workgroup conflict variable (e.g., Enders \& Tofighi, 2007). The model fit was tested by deriving $\mathrm{R}^{2}$, computed as the square of the correlation between the observed outcome and predicted fixed-effect outcome (Hoffman, 2015).

\section{Study 3: Results and Discussion}

The descriptive statistics and correlations among the study variables are presented in Table 6, and the HLM results are in Table 7. Model 1 of Table 7 shows that the squared victimization variable was not significant $(\gamma=-.16$, n.s.). Thus, Hypothesis 1 was not supported. 
Insert Tables 6-7 and Figure 8

To test Hypothesis 2, we added the interaction of the squared victimization term and workgroup conflict in Model 2, and the interaction term was significant $(\gamma=3.09, p<.05)$. Figure 8 shows the form of the interaction. As we expected, the relationship between victimization and forgiveness was inverted-U shaped when workgroup conflict was low, but the relationship was flat between victimization and forgiveness when workgroup conflict was high. The simple slope test showed that the squared simple slope $\left(\gamma_{\text {squared victimization under low conflict }}=-1.70\right.$, $p<.05)$ was significant when workgroup conflict was low. Yet, when workgroup conflict was high, neither the linear $\left(\gamma_{\text {linear victimization under high conflict }}=-.98\right.$, n.s. $)$ nor the squared $\left(\gamma_{\text {squared victimization }}\right.$ under high Conflict Squared $=1.39, p<.10$ ) terms were significant. Thus, Hypothesis 2 was supported.

As shown in Models 3 to 5 in Table 7, the mediating variable - forgiveness - was significantly related to job satisfaction $(\gamma=.13, p<.01)$, burnout $(\gamma=-.10, p<.05)$, and turnover intentions $(\gamma=-.09, p<.05)$. Table 8 shows the path analytic model results that are produced based on those estimates from Table 7. The indirect effects of victimization on workplace outcomes, through forgiveness, varied across levels of workgroup conflict. When workgroup conflict was low, the indirect curvilinear effects of victimization through forgiveness was significant for the job satisfaction model $\left(\mathrm{P}_{\mathrm{YM}} \mathrm{P}_{\mathrm{MX}}{ }^{2}=-.22, p<.05\right)$ and the burnout model $\left(\mathrm{P}_{\mathrm{YM}} \mathrm{P}_{\mathrm{MX}}{ }^{2}=.17, p<.05\right)$. However, the conditional indirect curvilinear effect was not significant for turnover intention $\left(\mathrm{P}_{\mathrm{YM}} \mathrm{P}_{\mathrm{MX}}{ }^{2}=.15, p<.10\right)$. This may be a function of little variation in turnover intentions generally among this sample. According to a high-level manager within the utility provider, the organization is seen as a highly desirable employer within the community, offering comparatively high wages, working conditions, and job security. When workgroup 
conflict was high, forgiveness did not mediate any of the effects of victimization on the three

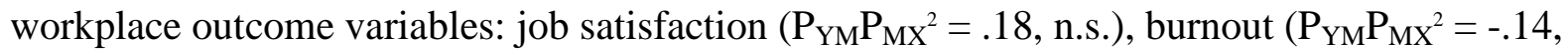
n.s.), and turnover intent $\left(\mathrm{P}_{\mathrm{YM}} \mathrm{P}_{\mathrm{MX}}{ }^{2}=-.12\right.$, n.s. $)$.

Insert Table 8 and Figures 9-10 about here

Figures 9 and 10 illustrate the total effects of victimization on burnout and job satisfaction through forgiveness at low and high workgroup conflict levels. Figure 9 shows that when workgroup conflict is low, the indirect effect between victimization and burnout through forgiveness takes a positive curvilinear form. However, when workgroup conflict is high, forgiveness does not mediate, and the graph of the total effect under high workgroup conflict is a positive linear relationship. Contrasting these total effects, the positive total effect is attenuated under low workgroup conflict as compared to high workgroup conflict. Figure 10 shows that the indirect effect of victimization on job satisfaction via forgiveness under low workgroup conflict takes a negative curvilinear form, and the effect without forgiveness mediating under high conflict is linear and negative. In comparison, the negative total effect is attenuated under low workgroup conflict. Hence, Hypothesis 3 was supported only for burnout and job satisfaction.

\section{Additional Analyses}

As in Study 1b, we collected data in Study 3 that included revenge, and, as a comparison to forgiveness, we conducted further analysis to see victimization and workgroup conflict's influence on revenge. As Study 3's results have shown, victimized customer service employees, working in low conflict workgroups, were able to forgive their aggressive customers but only until reaching an egregious victimization threshold. Our results also revealed that forgiveness predicts work attitudes beyond revenge. In contrast, the additional analyses have shown that 
victimization has a significant main effect on revenge but does not have a significant curvilinear effect. Further, workgroup conflict was not a boundary condition of the victimization-revenge relationship. This evidence implies that revenge increases with victimization. As a result, at egregious levels of victimization, victims may be more likely to pursue revenge than forgiveness, regardless of group conflict.

\section{General Discussion}

With COR theory, we argued that victimized human service employees can use cognitive control resources to replace their innate negative responses to being victimized with more positive emotions (e.g., empathy, compassion) which offer human service employees psychological benefits. Our research shows that human service employees’ capacity to forgive is curvilinear. Victimized human service employees are more likely to forgive at higher levels of victimization, but only up to a point. When victimization is at a sufficiently high level, forgiveness may prove too difficult to execute because the cognitive control resources required of the would-be forgiver exceed the resources they have available. This may be a result of human service workers’ compassion fatigue, i.e., stress experienced by caregivers as a result from caring for vulnerable clients (Figley, 1995), that reduces their “capacity or interest in being empathic” to clients (Adams, Boscarino, \& Figley, 2006, p. 103). If human service workers have depleted resources due to compassion fatigue, at egregious levels of victimization, they are likely unable to have the resources to forgive egregious victimizations. The self-protective function central to COR theory may also help to explain this result; egregious levels of victimization are clearly a threat to an employee's psychological well-being and, in some cases, physical safety. Further investment in the relationship via forgiveness may therefore be perceived as dangerous, and the employee may thus lack the motivation to forgive, seeking instead to conserve valuable well- 
being and safety resources. It seems likely that these explanations can account for the consistent curvilinear relationship between client-instigated victimization and forgiveness found in our experimental and field studies of human service workers. The replication of the curvilinear pattern in the first two studies provides evidence that the pattern is robust in human service work.

In contrast, this curvilinear relationship between victimization and forgiveness was not supported in our constructive replication of service employees not working in human services. Central to human service work is delivering compassion and care to clients, and, thus, employees in these caring professions likely are more sensitive to and aware of their clients' needs and conditions and have client interactions that can trigger compassionate responses (e.g., Rynes et al., 2012), such as forgiveness. It is possible that one factor that facilitates forgiveness among human service employees, whose clients may be vulnerable, is that these employees may be more sympathetic to their clients’ inability to regulate their behavior. Our constructive replication study represented a different type of service setting, where the clients' behavior may have been less easy to attribute to their physical or psychological conditions. In this setting, forgiving is likely to become even more cognitively demanding for employees, and our failure to replicate the non-linear relationship found with human service workers may indicate a lower threshold at which other service workers decide to abandon a forgiveness strategy in favor of other responses to victimization. This interpretation is supported by the fact that although we found no relationship in Study 1b between client victimization, workgroup conflict, and their interaction with avoidance and revenge for human service workers, revenge was shown to increase with victimization for customer service workers in the constructive replication.

It is also likely, however, that there are individual differences among employees in their tendency to forgive so that they are willing to attempt forgiveness even when victimization is 
extreme. Further, those who desire to get along and be liked by others may have greater motivation to continue forgiving as victimization increases than those who are disagreeable. Alternatively, individuals who are high in neuroticism or trait negative affect may experience stronger negative emotions from victimizations, making it difficult for them to have an otherfocus and the positive emotional change required for forgiveness. Or, individuals may possess greater compassionate dispositions by which they may rarely experience negative feelings toward perpetrators and, thus, do not need to engage in forgiveness. Still, both of these questions - how the nature of the service and client influences forgiveness and individual differences in forgiveness capabilities - are questions that should be addressed in future research.

In addition to the finding that forgiveness can be a viable coping option but is limited at egregious victimization levels, we determined that forgiveness also is limited for human service employees working in high conflict workgroups. This result extended to Study 3’s service workers who do not work in human services. Previous studies have examined other conditions that predict one's inability to forgive, such as excessive rumination over the event (McCullough, Bono, \& Root, 2007) and low levels of procedural justice (Aquino et al., 2006). Similar to workgroup conflict, these conditions are likely to compete with the threat of victimization and reduce the available cognitive control resources necessary to engage in the transformation of negative emotions to positive ones. We add to this list of “forgiveness inhibitors” by showing that experiencing conflict within one's workgroup can also make it difficult for employees to forgive clients. Given that one of the tenets of COR theory is that loss of resources is more salient than maintenance or replenishment of resources (Westman, Hobfoll, Chen, Davidson, \& Laski, 2004), future research may wish to investigate whether a positive climate (e.g., trust or collegiality) may be more effective in fostering forgiveness than simply the absence of a negative 
climate, as in conditions of low workgroup conflict.

Further, our finding that workgroup conflict moderated the relationship between victimization and forgiveness also supports a main argument made by Fehr and Gelfand (2012); namely, that contextual factors can influence individual-level forgiveness. Integrating our research with some of their key propositions offers practical implications for how managers might better equip employees to effectively deal with client-instigated victimization. If organizations and their managers establish workplace climates that better promote employees' forgiveness efforts (e.g., low conflict workgroups or those high in collegiality), employees may find themselves more readily engaging in forgiveness, or, at least, may observe other colleagues forgiving and the benefits that accrue to them. Through practice and/or observation and organizational reinforcement, employees may discern forgiveness as an appropriate and desirable way to respond to provocations. Thus a climate that, at first, fosters activation of forgiveness efforts may eventually transition to also encourage human service employees to think about forgiveness as a preferred method for dealing with abusive clients.

Our data support the notion that forgiveness has benefits for both employees and employers by showing that forgiveness was related to higher job satisfaction and lower emotional burnout and turnover intentions. Our research, though, went beyond finding forgiveness' main effects and explored it as a mediating mechanism. Typically, the literature on workplace victimization has emphasized its relationship with negative consequences (Aquino \& Thau, 2009; Bowling \& Beehr, 2006). Yet, how victims cope with their experiences as precursors of these consequences, especially in the client-instigated victimization literature, has received little attention (for an exception see Ben-Zur \& Yagil, 2005). Our research shows that given sufficient cognitive resources, the well-established connection between victimization and 
negative workplace outcomes need not always occur. In fact, we found that, under low conflict workgroups, the indirect relationship between client-instigated victimization and workplace outcomes, through forgiveness, generally followed a curvilinear pattern. Despite the costs to cognitive control resources incurred by forgiveness, resource gains in the form of positive cognitions and emotions rendered forgiveness an adaptive coping response through the lens of COR theory. In comparison, under a high workgroup conflict condition, forgiveness did not mediate, and the well-established negative connection between client-instigated victimization and consequences prevailed. The comparison of the plots for total effects under low and high workgroup conflict showed that the relationship under low workgroup conflict was attenuated. Obtaining these results among human service workers and service workers, in our constructive replication, in two different national contexts suggests that the findings are robust and generalizable to other service jobs and environments, further enhancing our contribution to the literature.

\section{Limitations and Future Directions}

Our studies have several strengths, including the use of experimental and field survey (i.e., multilevel and longitudinal) designs, large sample sizes of employees from real organizations and different occupations, and replication of findings within and across studies. However, like all studies, they also have limitations. First, our focus on client-instigated victimization as an antecedent to forgiveness, job satisfaction, emotional exhaustion, and turnover intentions precluded testing alternative theoretical models, such as organizational injustice, that are more often used to explain negative behavioral responses such as revenge or sabotage (e.g., Skarlicki et al., 2008). Given constructs captured in Study 2, we made an effort to preclude justice as an alternative explanation, and, thus, we conducted post-hoc analyses with 
two justice-related constructs as controls: trust in management and industrial relations climate. With the inclusion of these two additional variables, study results remained the same. Nonetheless, future work should investigate whether victims' prosocial responses are better facilitated in contexts that provide justice and harmony (Tripp, Bies, \& Aquino, 2007). In addition, we did not consider moderating factors in the work environment other than workplace conflict that could similarly promote competition for regulatory demand and cognitive control resources. Some of the factors that immediately come to mind include work overload, work complexity, work-family conflict, or employee perceptions of unfairness. Obviously, no study can cover all possible moderators or control for every likely antecedent to the dependent variables. Yet, workgroups are important to care delivery in many human service jobs. Given that workgroup conflict has been identified as one of the most harmful of work experiences, especially in human service work, and has been suggested as an impediment to forgiveness, workgroup conflict seemed like a reasonable construct to select as a basis for testing our predictions. Our specific interest in client-instigated victimization arose from conversations with human service workers, who indicated that workgroup conflict was a common experience. Although in Study 1a we found that participants who reflected on previous workgroup conflict reported greater levels of current resource depletion perceptions, our other studies did not explicitly capture the situation's cognitive load nor the individual's cognitive capacity. This current work would be complemented with further exploration of the moderating effect of cognitive load or capacity on the victimization-forgiveness relationship to strengthen the case for cognitive resources.

Future research could also consider how individual factors, such as self-concept, may impair employees’ abilities to forgive clients via depletion of cognitive control resources. For 
example, self-verification theory (Swann, 1987) has been invoked in research on abusive relationships to explain why individuals with low self-esteem are less likely to respond negatively to poor treatment. When treatment by another individual aligns with one's selfconcept (“I deserve to be treated this way”), positive attitudinal outcomes ensue (Shantz \& Booth, 2014). COR theory may provide another lens through which to interpret these results; when there is a high level of fit between mistreatment and self-concept, the cognitive resources necessary for forgiveness are more likely to be available, as they are not being deployed to reconcile self-beliefs with the perceived view of others. Self-concept may be an important element to test in future studies of forgiveness.

We acknowledge that there may be alternative, emotion-based explanations for the moderated, curvilinear relationship we found between victimization and forgiveness. For example, it may be that the stronger levels of threat incurred by higher levels of victimization prompt human service workers to narrow their attentional focus to the self, as a protective measure. As other-focus changes to self-focus, workgroup conflict may intensify the negative relationship between victimization and forgiveness because it increases the negative emotions experienced and contributes to the narrowing of human service workers' focus to the self. Changing negative to positive emotions and expanding one's focus to others (the clients) thus becomes more difficult, rendering forgiveness less likely.

Although our focus was specifically on client-instigated victimizations, future investigation should explore forgiveness’ role in other workplace relationships whose interactions are not directed by client service scripts. Furthermore, future studies may benefit by using other-report victimization measures in addition to self-report measures. In our study, we conceptualized victimization exposure as personally experienced because a precondition to 
forgiving is one's perception that s/he has been victimized. However, understanding how observers (i.e., witnesses) of victimizations perceive victimization episodes and how their perceptions could influence the actual victim’s forgiveness would be fruitful to the literature.

Other constructs related to forgiveness may also yield fruitful avenues of future study. For example, attribution theory holds that when individuals experience mistreatment, they engage in cognitive sense-making to determine how much responsibility should be attributed to the perpetrator (e.g., Aquino, Tripp, \& Bies, 2001; Bradfield \& Aquino, 1999). In the context of human service work, employees working with clients with mental health and/or developmental disabilities may be more understanding of transgressions, attribute less blame to the clients, and then engage in forgiveness as a result.

\section{Conclusion}

Taking a COR perspective on the victimization and forgiveness literature, we hypothesize and find in both experimental and field studies that the relationship between client victimizations and forgiveness takes the curvilinear form of an inverted-U - particularly in low conflict workgroups. Under high workgroup conflict, however, there was no systematic difference in forgiveness across victimization intensity levels. Additionally, in the field studies, we show that forgiveness mediates the victimization-workplace outcome relationship but only when workgroup conflict is low. Findings have important implications for victimization and forgiveness researchers and for employers and their managers. We urge future researchers to use the study as a point of departure for more comprehensive theories of victimization, forgiveness, workgroup conflict, and workplace outcomes. 


\section{References}

Adams, R. E., Boscarino, J. A., \& Figley, C. R. (2006). Compassion fatigue and psychological distress among social workers: a validation study. American Journal of Orthopsychiatry, 76(1), 103-108.

Aguinis, H., Gottfredson, R. K., \& Culpepper, S. A. (2013). Best-practice recommendations for estimating cross-level interaction effects using multilevel modeling. Journal of Management, 39(6), 1490-1528.

Alarcon, G. M. (2011). A meta-analysis of burnout with job demands, resources, and attitudes. Journal of Vocational Behavior, 79(2), 549-562.

Almost, J., Doran, D. M., McGillis Hall, L., \& Spence Laschinger, H. K. (2010). Antecedents and consequences of intra-group conflict among nurses. Journal of Nursing Management, 18(8), 981-992.

Aquino, K., \& Bradfield, M. (2000). Perceived victimization in the workplace: The role of situational factors and victim characteristics. Organization Science, 11(5), 525-537.

Aquino, K., Grover, S. L., Bradfield, M., \& Allen, D. G. (1999). The effects of negative affectivity, hierarchical status, and self-determination on workplace victimization. Academy of Management Journal, 42, 260-272.

Aquino, K., Grover, S. L., Goldman, B., \& Folger, R. (2003). When push doesn't come to shove interpersonal forgiveness in workplace relationships. Journal of Management Inquiry, 12(3), 209-216.

Aquino, K., \& Lamertz, K. (2004). A relational model of workplace victimization: social roles and patterns of victimization in dyadic relationships. Journal of Applied Psychology, 89(6), 1023.

Aquino, K., \& Thau, S. (2009). Workplace victimization: Aggression from the target's perspective. Annual Review of Psychology, 60, 717-741.

Aquino, K., Tripp, T. M., \& Bies, R. (2001). How employees respond to personal offense: The effects of blame attribution, victim status, and offense status on revenge and reconciliation in the workplace. Journal of Applied Psychology, 86, 52-59.

Aquino, K., Tripp, T. M., \& Bies, R. J. (2006). Getting even or moving on? Power, procedural justice, and types of offense as predictors of revenge, forgiveness, reconciliation, and avoidance in organizations. Journal of Applied Psychology, 91, 653-658. 
Arnetz, J. E., \& Arnetz, B. B. (2001). Violence towards health care staff and possible effects on the quality of patient care. Social Science \& Medicine, 52(3), 417-427.

Benight, C. C., Ironson, G., Klebe, K., Carver, C. S., Wynings, C., Burnett, K., Greenwood, D., Baum, A., \& Schneiderman, N. (1999). Conservation of resources and coping selfefficacy predicting distress following a natural disaster: A causal model analysis where the environment meets the mind. Anxiety, Stress and Coping, 12(2), 107-126.

Ben-Zur, H., \& Yagil, D. (2005). The relationship between empowerment, aggressive behaviours of customers, coping, and burnout. European Journal of Work and Organizational Psychology, 14, 81-99.

Blaney, P. H. (1986). Affect and memory: A review. Psychological Bulletin, 99, 229-246.

Bono, G., McCullough, M. E., \& Root, L. M. (2008). Forgiveness, feeling connected to others, and well-being: Two longitudinal studies. Personality and Social Psychology Bulletin, 34(2), 182-195.

Botvinick, M. M., Braver, T. S., Barch, D. M., Carter, C. S., \& Cohen, J. D. (2001). Conflict monitoring and cognitive control. Psychological Review, 108, 624-652.

Bowling, N. A., \& Beehr, T. A. (2006). Workplace harassment from the victim's perspective: A theoretical model and meta-analysis. Journal of Applied Psychology, 91, 998-1012.

Bradfield, M., \& Aquino, K. (1999). The effects of blame attributions and offender likableness on forgiveness and revenge in the workplace. Journal of Management, 25, 607-631.

Brislin, R. W. (1970). Back-translation for cross-cultural research. Journal of Cross-Cultural Psychology, 1(3), 185-216.

Brunero, S., Lamont, S., \& Coates, M. (2010). A review of empathy education in nursing. Nursing Inquiry, 17(1), 65-74.

Bryk, A., \& Raudenbush, S. W. (1992). Hierarchical linear models for social and behavioral research: applications and data analysis methods. Thousand Oaks, CA: Sage.

Bureau of Labor Statistics (2014). Occupational outlook handbook (OOH), 2012-2013 edition. U.S. Department of Labor. Retrieved from http://www.bls.gov/ooh/.

Bushman, B. J. (2002). Does venting anger feed or extinguish the flame? Catharsis, rumination, distraction, anger, and aggressive responding. Personality and Social Psychology Bulletin, 28, 724-731. 
Cammann, C., Fichman, M., Jenkins, D., \& Klesh, J. (1983). Assessing the attitudes and perceptions of organizational members. In S. Seashore, E. Lawler, P. Mirvis, \& C. Cammann (Eds.), Assessing organizational change: A guide to methods, measures and practices (pp. 71-138). New York, NY: Wiley.

Campbell, N. S., Perry, S. J., Maertz Jr, C. P., Allen, D. G., \& Griffeth, R. W. (2013). All you need is... resources: The effects of justice and support on burnout and turnover. Human Relations, 66(6), 759-782.

Carlsmith, K. M., Wilson, T. D., \& Gilbert, D. T. (2008). The paradoxical consequences of revenge. Journal of Personality and Social Psychology, 95(6), 1316-1324.

Cohen, J., Cohen, P., West, S. G., \& Aiken, L. S. (2003). Applied multiple regression correlation analysis for the behavioral sciences (3rd ed). Hillsdale: Erlbaum.

Cortina, L. M., \& Magley, V. J. (2003). Raising voice, risking retaliation: Events following interpersonal mistreatment in the workplace. Journal of Occupational Health Psychology, 8(4), 247-265.

Cox, S. S., Bennett, R. J., Tripp, T. M., \& Aquino, K. (2012). An empirical test of forgiveness motives' effects on employees' health and well-being. Journal of Occupational Health Psychology, 17(3), 330-340.

Cox, C. B., Johnson, J., \& Coyle, T. (2015). Coping styles moderate the relationships between exposure to community violence and work-related outcomes. Journal of Occupational Health Psychology, 20(3), 348-358.

Denson, T. F. (2009). Angry rumination and the self-regulation of aggression. In J. P. Forgas, R. F. Baumeister, \& D. M. Tice (Eds.), The psychology of self-regulation (pp. 233-248). New York, NY: Psychology Press.

Duffy, M. K., Ganster, D. C., Shaw, J. D., Johnson, J. L., \& Pagon, M. (2006). The social context of undermining behavior at work. Organizational Behavior and Human Decision Processes, 101, 105-126.

Edwards, J. R., \& Lambert, L.S. (2007). Methods for integrating moderation and mediation: A general analytical framework using moderated path analysis. Psychological Methods, 12, $1-22$.

Enders, C. K., \& Tofighi, D. (2007). Centering predictor variables in cross-sectional multilevel models: A new look at an old issue. Psychological Methods, 12, 121-138. 
Farrell, G. A. (1999). Aggression in clinical setting: Nurses’ views-a follow-up study. Journal of Advanced Nursing, 29(3), 532-541.

Fehr, R., \& Gelfand, M. J. (2012). The Forgiving Organization: A Multilevel Model of Forgiveness at Work. Academy of Management Review, 37, 664-688.

Fehr, R., Gelfand, M. J., \& Nag, M. (2010). The road to forgiveness: a meta-analytic synthesis of its situational and dispositional correlates. Psychological Bulletin, 136, 894-914.

Figley, C. R. (1995). Compassion fatigue: Toward a new understanding of the costs of caring. In B. H. Stamm (Ed), Secondary traumatic stress: Self-care issues for clinicians, researchers, and educators (pp. 3-28). Baltimore, MD: Sidran Press.

Finkel, E. J., Rusbbult, C. E., Kumashiro, M., \& Hannon, P. A. (2002). Dealing with betrayal in close relationships: Does commitment promote forgiveness? Journal of Personality and Social Psychology, 82, 956-974.

Friedman, R. A., Tidd, S. T., Currall, S. C., \& Tsai, J. C. (2000). What goes around comes around: The impact of personal conflict style on work conflict and stress. International Journal of Conflict Management, 11, 32-55.

Glick, W. H. (1985). Conceptualizing and measuring organizational and psychological climate: Pitfalls in multilevel research. Academy of Management Review, 10(3), 601-616.

Glomb, T. M., \& Liao, H. (2003). Interpersonal aggression in work groups: Social influence, reciprocal, and individual effects. Academy of Management Journal, 46, 486-496.

Gordon, K. C., \& Baucom, D. H. (1998). Understanding betrayals in marriage: A synthesized model of forgiveness. Family Process, 37(4), 425-449.

Gosling, S. D., Rentfrow, P. J., \& Swann, W. B., Jr. (2003). A very brief measure of the Big-Five personality domains. Journal of Research in Personality, 37, 504-528.

Grandey, A. A., Dickter, D. N., \& Sin, H. (2004). The customer is not always right: Customer aggression and emotion regulation of service employees. Journal of Organizational Behavior, 25, 397-418.

Grant, A. M., \& Schwartz, B. (2011). Too much of a good thing: The challenge and opportunity of the inverted U. Perspectives on Psychological Science, 6(1), 61-76.

Gross, J. J. (1998). Antecedent- and response-focused emotion regulation: Divergent consequences for experience, expression, and physiology. Journal of Personality and Social Psychology, 74(1), 224-237. 
Gross, J. J. (2015). Emotion regulation: Current status and future prospects. Psychological Inquiry, 26, 1-26.

Groth, M., \& Grandey, A. (2012). From bad to worse: Negative exchange spirals in employeecustomer service interactions. Organizational Psychology Review, 2, 208-233.

Han, G. H., \& Harms, P. D. (2010). Team identification, trust, and conflict: A mediation model. International Journal of Conflict Management, 21, 20-43.

Hellzen, O., Asplund, K., Gilje, F., Sandman, P. O., \& Norberg, A. (1998). From optimism to pessimism: A case study of a psychiatric patient. Journal of Clinical Nursing, 7(4), 360370.

Hellzen, O., Asplund, K., Sandman, P. O., \& Norberg, A. (1999). Unwillingness to be violated: Carers' experiences of caring for a person acting in a disturbing manner. An interview study. Journal of Clinical Nursing, 8(6), 653-662.

Higgins, E. T. (1996). The "self digest": Self-knowledge serving self-regulatory functions. Journal of Personality and Social Psychology, 71, 1062-1083.

Hobfoll, S. E. (1989). Conservation of resources: A new attempt at conceptualizing stress. American Psychologist, 44(3), 513-524.

Hobfoll, S. E. (2002). Social and psychological resources and adaptation. Review of General Psychology, 6(4), 307-324.

Hobfoll, S. E. (2011). Conservation of resources theory: Its implication for stress, health, and resilience. In S. Folkman \& P. E. Nathan (Eds.), The Oxford handbook of stress, health, and coping (pp. 127-147). New York: Oxford.

Hobfoll, S. E., \& Shirom, A. (1993). Stress and burnout in the workplace: Conservation of resources. In R. T. Golembiewski (Ed.), Handbook of organizational behavior (pp. 4161). New York, NY: Marcel Dekker, Inc.

Hoffman, L. (2015). Longitudinal analysis: Modeling within-person fluctuation and change. New York: Routledge.

Ito, J. K., \& Brotheridge, C. M. (2003). Resources, coping strategies, and emotional exhaustion: A conservation of resources perspective. Journal of Vocational Behavior, 63, 490-509.

Iverson, R. D., Olekalns, M, \& Erwin, P. J. (1998). Affectivity, organizational stressors, and absenteeism: A causal model of burnout and its consequences. Journal of Vocational Behavior, 52, 1-23. 
James, L. R. (1982). Aggregation in estimates of perceptual agreement. Journal of Applied Psychology, 67, 219-229.

James, L. R., Demaree, R. G., \& Wolf, G. (1993). Rwg: An assessment of within-group interrater agreement. Journal of Applied Psychology, 78, 306-309.

Jehn, K. A. (1995). A multimethod examination of the benefits and detriments of intragroup conflict. Administrative Science Quarterly, 40, 256-282.

Jehn, K., \& Mannix, E. (2001). The dynamic nature of conflict: A longitudinal study of intragroup conflict and group performance. Academy of Management Journal, 44, 238251.

Jex, S. M., \& Beehr, T. A. (1991). Emerging theoretical and methodological issues in the study of work-related stress. In K. Rowland \& G. Ferris (Eds.), Research in Personnel and Human Resources Management (p.311-365). Greenwich, CT: JAI Press.

Karremans, J. C., \& Aarts, H. (2007). The role of automaticity in determining the inclination to forgive close others. Journal of Experimental Social Psychology, 43, 902-917.

Karremans, J. C., \& van der Wal, R. C. (2013). It takes more to forgive: The role of executive control. Behavioral and Brain Sciences, 36(1), 25.

Karremans, J. C., Van Lange, P. A., \& Holland, R. W. (2005). Forgiveness and its associations with prosocial thinking, feeling, and doing beyond the relationship with the offender. Personality and Social Psychology Bulletin, 31, 1315-1326.

Karremans, J. C., Van Lange, P. A. M., Ouwerkerk, J. W., \& Kluwer, E. S. (2003). When forgiving enhances psychological well-being: The role of interpersonal commitment. Journal of Personality and Social Psychology, 84, 1011-1026.

Kelloway, E. K., Catano, V. M., \& Southwell, R. R. (1992). The construct validity of union commitment: Development and dimensionality of shorter scale. Journal of Occupational \& Organizational Psychology, 65, 197-211.

Kozlowski, S. W. J., \& Klein, K. J. (2000). A multilevel approach to theory and research in organizations. In K. J. Klein \& S. W. J. Kozlowski (Eds.), Multilevel theory, research, and methods in organizations (pp. 3-90). San Francisco, CA: Jossey-Bass.

Lanza, M. L., \& Carifio, J. (1990). The use of control vignettes. Journal of Nursing Scholarship, 22, 231-234.

Lazarus, R. S., \& Folkman, S. (1984). Stress, appraisal, and coping. New York, NY: Springer. 
Leiter, M. P. (1991). Coping patterns as predictors of burnout: The function of control and escapist coping patterns. Journal of Organizational Behavior, 12(2), 123-144.

Liu, Y., Wang, M., Chang, C. H., Shi, J., Zhou, L., \& Shao, R. (2015). Work-family conflict, emotional exhaustion, and displaced aggression toward others: The moderating roles of workplace interpersonal conflict and perceived managerial family support. Journal of Applied Psychology, 100(3), 793-808.

Lykken, D. T. (1968). Statistical significance in psychological research. Psychological Bulletin, 70(3), 151-159.

MacKinnon, D. P., Fairchild, A. J., \& Fritz, M. S. (2007). Mediation analysis. Annual Review of Psychology, 58, 593-614.

Magley, V. J., Hulin, C. L., Fitzgerald, L. F., \& DeNardo, M. (1999). Outcomes of self-labeling sexual harassment. Journal of Applied Psychology, 84(3), 390-402.

Mathison, S. (1988). Why triangulate?. Educational Researcher, 17(2), 13-17.

McCullough, M. E., Bono, G., \& Root, L. M. (2007). Rumination, emotion, and forgiveness: Three longitudinal studies. Journal of Personality and Social Psychology, 92, 490-505.

McCullough, M. E., Fincham, F. D., \& Tsang, J. (2003). Forgiveness, forbearance, and time: The temporal unfolding of transgression-related interpersonal motivations. Journal of Personality and Social Psychology, 84, 540-557.

McCullough, M. E., Rachal, K. C., Sandage, S. J., Worthington, E. L., Jr., Brown, S. W., \& Hight, T. L. (1998). Interpersonal forgiving in close relationships: II. Theoretical elaboration and measurement. Journal of Personality and Social Psychology, 75, 15861603.

Needham, I., Abderhalden, C., Halfens, R. J., Fischer, J. E., \& Dassen, T. (2005). Non- somatic effects of patient aggression on nurses: A systematic review. Journal of Advanced Nursing, 49(3), 283-296.

Nolen-Hoeksema, S., Parker, L. E., \& Larson, J. (1994). Ruminative coping with depressed mood following loss. Journal of Personality and Social Psychology, 67(1), 92-104.

O'Leary-Kelly, A. M., Bowes-Sperry, L., Bates, C. A., \& Lean, E. R. (2009). Sexual harassment at work: A decade (plus) of progress. Journal of Management, 35(3), 503-536.

Ostroff, C., \& Schmitt, N. (1993). Configurations of organizational effectiveness and efficiency. Academy of Management Journal, 36, 1345-1361. 
Payne, B. K. (2005). Conceptualizing control in social cognition: How executive function modulates the expression of automatic stereotyping. Journal of Personality and Social Psychology, 89, 488-503.

Porath, C. L., \& Erez, A. (2007). Does rudeness really matter? The effects of rudeness on task performance and helpfulness. Academy of Management Journal, 50, 1181-1197.

Pronk, T. M., Karremans, J. C., Overbeek, G., Vermulst, A. A., \& Wigboldus, D. H. (2010). What it takes to forgive: When and why executive functioning facilitates forgiveness. Journal of Personality and Social Psychology, 98, 119-131.

Radey, M., \& Figley, C. R. (2007). The social psychology of compassion. Clinical Social Work Journal, 35(3), 207-214.

Rafaeli, A., Erez, A., Ravid, S., Derfler-Rozin, R., \& Efrat-Treister, R. (2012). When customers exhibit verbal aggression, employees pay cognitive costs. Journal of Applied Psychology, 97, 931-950.

Rasmussen, C. A., Hogh, A., \& Andersen, L. P. (2013). Threats and Physical Violence in the Workplace A Comparative Study of Four Areas of Human Service Work. Journal of Interpersonal Violence, 28(13), 2749-2769.

Reynolds, K. L., \& Harris, L. C. (2006). Deviant customer behavior: An exploration of frontline employee tactics. Journal of Marketing Theory and Practice, 14, 95-111.

Riek, B. M., \& Mania, E. W. (2011). The antecedents and consequences of interpersonal forgiveness: A meta-analytic review. Personal Relationships, 19, 304-325.

Rogers, K., \& Kelloway, E. K. (1997). Violence at work: Personal and organizational outcomes. Journal of Occupational Health Psychology, 2, 63-71.

Rowe, M., \& Sherlock, H. (2005). Stress and verbal abuse in nursing: Do burned out nurses eat their young?. Journal of Nursing Management, 13(3), 242-248.

Rynes, S. L., Bartunek, J. M., Dutton, J. E., \& Margolis, J. D. (2012). Care and compassion through an organizational lens: Opening up new possibilities. Academy of Management Review, 37(4), 503-523.

Sasaki, S. J., \& Vorauer, J. D. (2010). Contagious resource depletion and anxiety? Spreading effects of evaluative concern and impression formation in dyadic social interaction. Journal of Experimental Social Psychology, 46(6), 1011-1016. 
Sandage, S., \& Worthington Jr, E. (2010). Comparison of two group interventions to promote forgiveness: Empathy as a mediator of change. Journal of Mental Health Counseling, 32(1), 35-57.

Schaufeli, W. B., \& Buunk, B. P. (2003). Burnout: An overview of 25 years of research and theorizing. In M. J. Schabracq, J. A. M. Winnubst, \& C. L. Cooper (Eds.), The handbook of work and health psychology ( $2^{\text {nd }}$ ed.) (pp. 383-425). Chichester: Wiley.

Schneider, B., Ehrhart, M. G., Mayer, D. M., Saltz, J. L., \& Niles-Jolly, K. (2005). Understanding organization-customer links in service settings. Academy of Management Journal, 48, 1017-1032.

Schneider, B., White, S. S., \& Paul, M. C. (1998). Linking service climate and customer perceptions of service quality: Tests of a causal model. Journal of Applied Psychology, 83, 150-163.

Selig, J. P., \& Preacher, K. J. (2008, June). Monte Carlo method for assessing mediation: An interactive tool for creating confidence intervals for indirect effects [Computer software]. Available from http://quantpsy.org/

Shantz, A., \& Booth, J. E. (2014). Service employees and self-verification: The roles of occupational stigma consciousness and core self-evaluations. Human Relations, 67, 14391465.

Si, S. X., \& Cullen, J. B. (1998). Response categories and potential cultural bias: Effects of an explicit middle point in cross-cultural surveys. The International Journal of Organizational Analysis, 6(3), 218-230.

Sinclair, R. R., Martin, J. E., \& Croll, L. W. (2002). A threat-appraisal perspective on employees' fears about antisocial workplace behavior. Journal of Occupational Health Psychology, 7(1), 37-56.

Skarlicki, D. P., Van Jaarsveld, D. D., \& Walker, D. D. (2008). Getting even for customer mistreatment: the role of moral identity in the relationship between customer interpersonal injustice and employee sabotage. Journal of Applied Psychology, 93(6), 1335-1347.

Sliter, M. T., Pui, S. Y., Sliter, K. A., \& Jex, S. M. (2011). The differential effects of interpersonal conflict from customers and coworkers: Trait anger as a moderator. Journal of Occupational Health Psychology, 16, 424-440. 
Spence Laschinger, H. K., Leiter, M., Day, A., \& Gilin, D. (2009). Workplace empowerment, incivility, and burnout: Impact on staff nurse recruitment and retention outcomes. Journal of Nursing Management, 17, 302-311.

Stephen, K. A., \& Baernstein, A. (2006). Educating for empathy. Journal of General Internal Medicine, 21(5), 524-530.

Strelan, P. (2007). Who forgives others, themselves, and situations? The roles of narcissism, guilt, self-esteem, and agreeableness. Personality and Individual Differences, 42(2), 259269.

Strelan, P., \& Covic, T. (2006). A review of forgiveness process models and a coping framework to guide future research. Journal of Social and Clinical Psychology, 25(10), 1059-1085.

Swann, W. B. Jr (1987). Identity negotiation: Where two roads meet. Journal of Personality and Social Psychology, 53, 1038-1051.

Terry, A. A. (1998). Teachers as targets of bullying by their pupils: A study to investigate incidence. British Journal of Educational Psychology, 68(2), 255-268.

Tripp, T. M., Bies, R. J., \& Aquino, K. (2007). A vigilante model of justice: Revenge, reconciliation, forgiveness, and avoidance. Social Justice Research, 20, 10-34.

Twigg, N. W., Fuller, J. B., \& Hester, K. (2008). Transformational leadership in labor organizations: the effects on union citizenship behaviors. Journal of Labor Research, 29, 27-41.

Vachon, M. L. S., \& Müeller, M. (2009). Burnout and symptoms of stress. In Breitbart, W. \& Chochinov, H. M. (Eds.). Handbook of psychiatry in palliative medicine (pp. 559-625). New York, NY: Oxford University Press.

Van der Wal, R. C., Karremans, J. C., \& Cillessen, A. H. N. (2012). A dual-process perspective on interpersonal forgiveness. Unpublished data.

van Rensburg, E. J., \& Raubenheimer, J. (2015). Does forgiveness mediate the impact of school bullying on adolescent mental health?. Journal of Child \& Adolescent Mental Health, 27(1), 25-39.

Wang, M., Liao, H., Zhan, Y., \& Shi, J. (2011). Daily customer mistreatment and employee sabotage against customers: Examining emotion and resource perspectives. Academy of Management Journal, 54, 312-334. 
Wanous, J. P., Reichers, A. E., \& Hudy, M. J. (1997). Overall job satisfaction: How good are single-item measures? Journal of Applied Psychology, 82, 247-252.

Wasti, S. A., \& Cortina, L. M. (2002). Coping in context: Sociocultural determinants of responses to sexual harrassment. Journal of personality and social psychology, 83(2), 394-405.

Webb, E. J., Campbell, D. T., Schwartz, R. D., \& Sechrest, L. (1966). Unobtrusive measures: Nonreactive research in the social sciences. Chicago: Rand McNally.

Westman, M., Hobfoll, S. E., Chen, S., Davidson, O. B., \& Laski, S. (2004). Organizational stress through the lens of conservation of resources (COR) theory. Research in Occupational Stress and Well Being, 4, 167-220.

Wichman, A. L., Brunner, R. P, \& Weary, G. (2008). Immediate and delayed effects of causal uncertainty inductions on uncertainty accessibility. Journal of Experimental Social Psychology, 44, 1106-1113.

Wilkowski, B. M., Robinson, M. D., \& Troop-Gordon, W. (2010). How does cognitive control reduce anger and aggression? The role of conflict monitoring and forgiveness processes. Journal of Personality and Social Psychology, 98(5), 830-840.

Witvliet, C. V. O., Ludwig, T. E., \& Laan, K. L. V. (2001). Granting forgiveness or harboring grudges: Implications for emotion, physiology, and health. Psychological Science, 12(2), 117-123.

Worthington Jr, E. L. (2006). Forgiveness and reconciliation: Theory and application. Abingdon: Routledge.

Worthington, E. L., Jr., \& Scherer, M. (2004). Forgiveness as an emotion-focused coping strategy that can reduce health risks and promote health resilience: Theory, review, and hypotheses. Psychology and Health, 19, 385-405.

Yagil, D. (2008). When the customer is wrong: A review of research on aggression and sexual harassment in service encounters. Aggression and Violent Behavior, 13, 141-152. 
Table 1

Summary of ANOVA results for Study $\mathbf{1 b}$

\begin{tabular}{|c|c|c|c|c|}
\hline & $\begin{array}{c}\text { Partial } \\
\text { SS }\end{array}$ & df & MS & $\mathrm{F}$ \\
\hline Model & 45.45 & 5 & 9.09 & $3.96 * *$ \\
\hline Victimization Severity & 18.27 & 2 & 9.14 & $3.98 *$ \\
\hline Workgroup Conflict & 5.59 & 1 & 5.59 & 2.44 \\
\hline Interaction & 16.7 & 2 & 8.35 & $3.64 *$ \\
\hline Residual & 433.47 & 189 & 2.29 & \\
\hline Total & 478.92 & 194 & 2.47 & \\
\hline
\end{tabular}


Table 2

Summary of means for forgiveness in low, medium, and high victimization conditions as well as in high and low workgroup conflict conditions respectively.

Overall

Low Victimization Severity

$4.28(1.55)$

Medium Victimization Severity

High Victimization Severity

Significance $F$ Test from ANOVA

$$
5.02 \text { (1.43) }
$$

$\mathrm{F}(2,189)=3.98, \mathrm{p}<.05$
Low Workgroup Conflict

4.28 (1.56)

$5.53(1.26)$

$4.25(1.45)$
High Workgroup Conflict

4.27 (1.57)

4.37 (1.39)

4.38 (1.78)

Standard deviations are reported in parenthesis. 
Table 3

Study 2: Correlations and descriptive statistics

\begin{tabular}{|c|c|c|c|c|c|c|c|c|c|c|c|c|c|c|}
\hline & Mean & SD & 1. & 2. & 3. & 4. & 5. & 6. & 7. & 8. & 9. & 10. & 11. & 12. \\
\hline 1.Age & 41.70 & 13.91 & & & & & & & & & & & & \\
\hline 2.Education & 3.07 & .87 & $-.13^{*}$ & & & & & & & & & & & \\
\hline 3.Tenure & 8.88 & 9.16 & $.54^{* *}$ & -.11 & & & & & & & & & & \\
\hline 4.Neuroticism & 2.26 & .77 & .00 & -.04 & .09 & & & & & & & & & \\
\hline 5.Care for disabilities & 3.85 & 1.26 & -.05 & -.04 & .09 & .06 & & & & & & & & \\
\hline 6.Shift size & 5.26 & 3.82 & -.03 & .00 & .01 & -.02 & -.02 & & & & & & & \\
\hline 7.Agreeableness & 4.09 & .71 & .08 & .08 & -.01 & $-.40 * *$ & -.07 & .09 & & & & & & \\
\hline 8.Victimization & 2.30 & 1.13 & $-.19 * *$ & -.00 & -.05 & $.19 * *$ & $.17^{* *}$ & .04 & $-.15^{*}$ & & & & & \\
\hline 9.Forgiveness & 3.41 & 1.09 & .02 & .00 & -.12 & -.11 & .13 & .02 & $.16^{*}$ & .00 & & & & \\
\hline 10.Workgroup conflict & 2.66 & .64 & -.04 & -.03 & .04 & .08 & .07 & .10 & .07 & $.18^{* *}$ & .01 & & & \\
\hline 11.Job satisfaction & 3.56 & 1.01 & $.13^{*}$ & $-.18 * *$ & -.04 & $-.14^{*}$ & -.11 & .03 & .02 & $-.27 * *$ & .16 & $-.34 * *$ & & \\
\hline 12.Burnout & 3.29 & 1.12 & -.04 & .02 & $.15^{*}$ & $.20^{* *}$ & $.20 * *$ & -.06 & $-.14 *$ & $.31^{* *}$ & $-.17^{* *}$ & $.30 * *$ & $-.53 * *$ & \\
\hline 13.Turnover intentions & 2.28 & 1.08 & $-.39 * *$ & $.18^{* *}$ & $-.30 * *$ & .04 & -.05 & -.08 & -.07 & $.17^{* *}$ & -.13 & $.27^{* *}$ & $-.49 * *$ & $.27 * *$ \\
\hline
\end{tabular}

Notes: ${ }^{*} p<.05,{ }^{* *} p<.01 . n=241-248$. Two-tailed. 
Table 4

Study 2: Multilevel Linear Modeling Results

\begin{tabular}{|c|c|c|c|c|c|}
\hline & \multicolumn{2}{|c|}{ Forgiveness } & \multirow{2}{*}{$\begin{array}{c}\text { Job Satisfaction } \\
\text { Model } 3\end{array}$} & \multirow{2}{*}{$\begin{array}{l}\text { Burnout } \\
\text { Model } 4\end{array}$} & \multirow{2}{*}{$\begin{array}{c}\text { Turnover } \\
\text { Intention } \\
\text { Model } 5 \\
\end{array}$} \\
\hline & Model 1 & Model 2 & & & \\
\hline \multicolumn{6}{|l|}{ Controls } \\
\hline \multirow[t]{2}{*}{ Age } & $.01+$ & $.01 *$ & .01 & -.00 & $-.02 * *$ \\
\hline & $(.01)$ & $(.01)$ & $(.01)$ & $(.01)$ & $(.01)$ \\
\hline \multirow[t]{2}{*}{ Education } & .03 & .02 & $-.22 * *$ & .06 & $.18^{*}$ \\
\hline & $(.08)$ & $(.07)$ & $(.06)$ & $(.07)$ & $(.09)$ \\
\hline \multirow[t]{2}{*}{ Tenure } & $-.02 * *$ & $-.02 *$ & -.01 & $.02 *$ & $-.02 *$ \\
\hline & $(.01)$ & $(.01)$ & $(.01)$ & $(.01)$ & $(.01)$ \\
\hline \multirow[t]{2}{*}{ Neuroticism } & -.01 & -.03 & -.06 & .14 & -.04 \\
\hline & $(.09)$ & $(.09)$ & $(.10)$ & $(.11)$ & $(.09)$ \\
\hline \multirow[t]{2}{*}{ Care for disabilities } & .08 & .06 & -.07 & $.10 *$ & -.05 \\
\hline & $(.05)$ & $(.05)$ & $(.04)$ & $(.05)$ & $(.04)$ \\
\hline \multirow[t]{2}{*}{ Shift size } & -.01 & -.01 & $.03 *$ & -.01 & $-.03 *$ \\
\hline & $(.01)$ & $(.01)$ & $(.01)$ & $(.01)$ & $(.01)$ \\
\hline \multirow[t]{2}{*}{ Agreeableness } & $.24^{*}$ & $.23^{*}$ & -.07 & -.14 & -.05 \\
\hline & $(.10)$ & $(.10)$ & $(.10)$ & $(.09)$ & $(.09)$ \\
\hline \multirow[t]{2}{*}{ Workgroup average victimization } & $1.70^{*}$ & $1.95^{* * *}$ & .17 & -.01 & .62 \\
\hline & $(.67)$ & $(.62)$ & $(.75)$ & $(.64)$ & $(.69)$ \\
\hline \multirow[t]{2}{*}{ Workgroup average victimization ${ }^{2}$} & $-.28 *$ & $-.33 * *$ & -.10 & .07 & -.10 \\
\hline & $(.13)$ & $(.12)$ & $(.16)$ & $(.13)$ & $(.15)$ \\
\hline \multicolumn{6}{|l|}{ Independent variables } \\
\hline \multirow[t]{2}{*}{ Workgroup conflict } & -.13 & $-.25+$ & $-.58 * *$ & $.45^{* *}$ & $.50 * *$ \\
\hline & $(.15)$ & $(.14)$ & $(.15)$ & $(.14)$ & $(.16)$ \\
\hline \multirow[t]{2}{*}{ Victimization } & .10 & $.20 *$ & -.07 & .15 & -.06 \\
\hline & $(.08)$ & $(.10)$ & $(.11)$ & $(.11)$ & $(.07)$ \\
\hline \multirow[t]{2}{*}{ Victimization $^{2}$} & $-.13 * *$ & $-.23 * *$ & .00 & .01 & .05 \\
\hline & $(.05)$ & $(.06)$ & $(.07)$ & $(.05)$ & $(.05)$ \\
\hline \multicolumn{6}{|l|}{ Interaction variables } \\
\hline \multirow[t]{2}{*}{ Victimization $\times$ Workgroup conflict } & & $-.40 *$ & -.08 & -.08 & -.05 \\
\hline & & $(.19)$ & $(.20)$ & $(.22)$ & $(.13)$ \\
\hline \multirow[t]{2}{*}{ Victimization $^{2} \times$ Workgroup conflict } & & $.30 *$ & .02 & .08 & .01 \\
\hline & & $(.12)$ & $(.12)$ & $(.09)$ & $(.09)$ \\
\hline \multicolumn{6}{|l|}{ Mediator } \\
\hline \multirow[t]{2}{*}{ Forgiveness } & & & $.15^{*}$ & $-.16^{*}$ & $-.12 *$ \\
\hline & & & $(.06)$ & $(.07)$ & $(.06)$ \\
\hline Log Likelihood & $-303.43 * *$ & $-300.32 * *$ & $-267.96 * *$ & $-291.46 * *$ & $-279.09 * *$ \\
\hline $\mathrm{R}^{2}$ & .09 & .10 & .25 & .22 & .26 \\
\hline
\end{tabular}

Notes: $\dagger p<.10,{ }^{*} p<.05,{ }^{* *} p<.01$. Two-tailed. Employees $n=213$. Group $n=53$. $\gamma$-coefficients are reported. The log likelihood is a measure of overall model goodness-of-fit. The log likelihood value is always negative, with higher values (closer to zero) indicating a better fitting model. 
Table 5

Study 2: Path Analytic Results

\begin{tabular}{|c|c|c|c|c|c|c|c|}
\hline & \multicolumn{2}{|c|}{ First Stage } & Second Stage & \multicolumn{2}{|c|}{ Direct Effects } & \multicolumn{2}{|c|}{ Indirect Effects } \\
\hline & $\mathrm{P}_{\mathrm{MX}}(\mathrm{SE})$ & $\mathrm{P}_{\mathrm{MX}}^{2}(\mathrm{SE})$ & $\mathrm{P}_{\mathrm{YM}} \quad(\mathrm{SE})$ & $(\mathrm{SE})$ & $\mathrm{P}_{\mathrm{YX}}^{2}(\mathrm{SE})$ & $\mathrm{P}_{\mathrm{YM}} \mathrm{P}_{\mathrm{MX}}(95 \%)$ Confidence Interval $)$ & $\mathrm{P}_{\mathrm{YM}} \mathrm{P}_{\mathrm{MX}}{ }^{2(95 \%}$ Confidence Interval) \\
\hline Job Satisfaction & & & & & & & \\
\hline High group conflict & $-.04(.09)$ & $-.05(.05)$ & $.15(.06)^{* *}$ & $-.07(.11)$ & $.00(.07)$ & $-.01(-.04, .02)$ & $-.01(-.03, .01)$ \\
\hline Low group conflict & $.44(.19) * *$ & $-.12(.00) * *$ & $.15(.06)^{* *}$ & $-.07(.11)$ & $.00(.07)$ & $.07(.00, .16)^{*}$ & $-.06(-.13,-.01)^{*}$ \\
\hline \multicolumn{8}{|l|}{ Burnout } \\
\hline High group conflict & $-.04(.09)$ & $-.05(.05)$ & $-.16(.07)^{*}$ & $.15(.11)$ & $.01(.05)$ & $.01(-.03, .04)$ & $.01(-.01, .03)$ \\
\hline Low group conflict & $.44(.19)^{* *}$ & $-.12(.00)^{* *}$ & $-.16(.07)^{*}$ & $.15(.11)$ & $.01(.05)$ & $-.07(-.17,-.00)^{*}$ & $.07(.01, .15)^{*}$ \\
\hline \multicolumn{8}{|l|}{ Turnover Intentions } \\
\hline High group conflict & $-.04(.09)$ & $-.05(.05)$ & $-.12(.06)^{*}$ & $-.06(.07)$ & $.05(.26)$ & $.00(-.02, .03)$ & $.01(-.01, .02)$ \\
\hline Low group conflict & $.44(.19) * *$ & $-.12(.00) * *$ & $-.12(.06)^{*}$ & $-.06(.07)$ & $.05(.26)$ & $-.05(-.15, .00)$ & $.05(.00, .12) *$ \\
\hline
\end{tabular}


Table 6

Study 3: Correlations and descriptive statistics

\begin{tabular}{|c|c|c|c|c|c|c|c|c|c|c|c|c|c|}
\hline & Mean & SD & 1. & 2. & 3. & 4. & 5. & 6. & 7. & 8. & 9. & 10. & 11. \\
\hline 1.Age & 43.35 & 7.91 & & & & & & & & & & & \\
\hline 2.Education & 2.39 & .88 & $-.62^{* *}$ & & & & & & & & & & \\
\hline 3.Tenure & 17.61 & 7.75 & $.62^{* *}$ & $-.30 * *$ & & & & & & & & & \\
\hline 4.Neuroticism & 2.98 & .99 & -.11 & -.09 & -.06 & & & & & & & & \\
\hline 5.Agreeableness & 3.99 & 1.03 & $.15^{*}$ & -.14 & .11 & $-.59 * *$ & & & & & & & \\
\hline 6.Revenge & 1.28 & .49 & $.14^{* *}$ & $-.21 * *$ & -.03 & $.37 * *$ & $-.19 * *$ & & & & & & \\
\hline 7.Victimization & 1.40 & .38 & .02 & $-.16^{* *}$ & -.08 & $.26^{* *}$ & -.07 & $.52^{* *}$ & & & & & \\
\hline 8.Workgroup conflict & 2.30 & .38 & $.14^{*}$ & -.11 & .01 & -.10 & .06 & -.04 & $.16^{* *}$ & & & & \\
\hline 9.Forgiveness & 3.40 & 1.52 & -.01 & $.26^{* *}$ & .02 & $-.34 * *$ & $.20 * *$ & $-.22 * *$ & $-.24 * *$ & $-.24 * *$ & & & \\
\hline 10.Job satisfaction & 4.51 & 1.11 & .09 & .04 & .07 & $-.30 *$ & $.23 * *$ & $-.43 * *$ & $-.41 * *$ & $-.14 * *$ & $.40^{* *}$ & & \\
\hline 11.Burnout & 3.03 & 1.22 & -.05 & .00 & $-.12 *$ & $.12 *$ & $.12 *$ & .06 & $.19^{* *}$ & -.09 & .00 & .05 & \\
\hline 12.Turnover intentions & 2.46 & 1.07 & $-.22 * *$ & .07 & $-.21^{* *}$ & $.25^{* *}$ & $-.12 *$ & $.16^{* *}$ & $.34^{* *}$ & -.04 & $-.18^{* *}$ & $-.19^{* *}$ & $.49^{* *}$ \\
\hline
\end{tabular}


Table 7

Study 3: Multilevel Linear Modeling Results

\begin{tabular}{|c|c|c|c|c|c|}
\hline & \multicolumn{2}{|c|}{ Forgiveness } & \multirow{2}{*}{$\begin{array}{c}\text { Job } \\
\text { Satisfaction } \\
\text { Model } 3 \\
\end{array}$} & \multirow{2}{*}{$\begin{array}{l}\text { Burnout } \\
\text { Model } 4 \\
\end{array}$} & \multirow{2}{*}{$\begin{array}{c}\text { Turnover } \\
\text { Intentions } \\
\text { Model } 5 \\
\end{array}$} \\
\hline & Model 1 & Model 2 & & & \\
\hline Age & $\begin{array}{c}.01 \\
(.02)\end{array}$ & $\begin{array}{c}.01 \\
(.03)\end{array}$ & $\begin{array}{c}.01 \\
(.01)\end{array}$ & $\begin{array}{c}.01 \\
(.02)\end{array}$ & $\begin{array}{l}-.02 \\
(.02)\end{array}$ \\
\hline Education & $\begin{array}{l}.66 * * \\
(.19)\end{array}$ & $\begin{array}{l}.67 * * \\
(.19)\end{array}$ & $\begin{array}{l}-.06 \\
(.11)\end{array}$ & $\begin{array}{c}.18 \\
(.16)\end{array}$ & $\begin{array}{c}.07 \\
(.14)\end{array}$ \\
\hline Tenure & $\begin{array}{c}.02 \\
(.02)\end{array}$ & $\begin{array}{c}.02 \\
(.02)\end{array}$ & $\begin{array}{l}.00 \\
(.01)\end{array}$ & $\begin{array}{l}-.03+ \\
(.02)\end{array}$ & $\begin{array}{l}-.01 \\
(.02)\end{array}$ \\
\hline Neuroticism & $\begin{array}{l}-.38+ \\
(.20)\end{array}$ & $\begin{array}{l}-.35+ \\
(.21)\end{array}$ & $\begin{array}{l}-.21+ \\
(.11)\end{array}$ & $\begin{array}{c}.26 \\
(.17)\end{array}$ & $\begin{array}{l}.12 \\
(.14)\end{array}$ \\
\hline Agreeableness & $\begin{array}{l}.18 \\
(.16)\end{array}$ & $\begin{array}{c}.14 \\
(.17)\end{array}$ & $\begin{array}{c}.05 \\
(.09)\end{array}$ & $\begin{array}{l}.30 * \\
(.14)\end{array}$ & $\begin{array}{c}.00 \\
(.11)\end{array}$ \\
\hline Revenge & $\begin{array}{l}-.05 \\
(.16)\end{array}$ & $\begin{array}{l}-.04 \\
(.15)\end{array}$ & $\begin{array}{c}-.43^{* *} \\
(.12)\end{array}$ & $\begin{array}{l}-.22 \\
(.14)\end{array}$ & $\begin{array}{l}-.01 \\
(.12)\end{array}$ \\
\hline Between-individual victimization & $\begin{array}{c}-.63 \\
(12.09)\end{array}$ & $\begin{array}{c}-1.97 \\
(12.69)\end{array}$ & $\begin{array}{c}-17.33^{*} \\
(6.94)\end{array}$ & $\begin{array}{l}-1.40 \\
(1.29)\end{array}$ & $\begin{array}{c}-.53 \\
(8.85)\end{array}$ \\
\hline Between-individual victimization ${ }^{2}$ & $\begin{array}{c}.47 \\
(4.59)\end{array}$ & $\begin{array}{c}1.06 \\
(4.83)\end{array}$ & $\begin{array}{l}6.19 * \\
(2.62)\end{array}$ & $\begin{array}{c}.93 \\
(3.89)\end{array}$ & $\begin{array}{c}.77 \\
(3.37)\end{array}$ \\
\hline Independent variables & & & & & \\
\hline Workgroup conflict & $\begin{array}{l}-.51 \\
(.37)\end{array}$ & $\begin{array}{l}-.76+ \\
(.39)\end{array}$ & $\begin{array}{l}-.29 \\
(.22)\end{array}$ & $\begin{array}{l}-.23 \\
(.33)\end{array}$ & $\begin{array}{l}-.17 \\
(.27)\end{array}$ \\
\hline Within-individual victimization & $\begin{array}{l}-.34 \\
(.48)\end{array}$ & $\begin{array}{l}-.38 \\
(.43)\end{array}$ & $\begin{array}{l}-.99 * * \\
(.37)\end{array}$ & $\begin{array}{l}.71+ \\
(.40)\end{array}$ & $\begin{array}{l}.78^{* *} \\
(.25)\end{array}$ \\
\hline Within-individual victimization ${ }^{2}$ & $\begin{array}{l}-.16 \\
(.60)\end{array}$ & $\begin{array}{l}-.15 \\
(.44)\end{array}$ & $\begin{array}{l}.85+ \\
(.50)\end{array}$ & $\begin{array}{l}-.18 \\
(.44)\end{array}$ & $\begin{array}{l}-.14 \\
(.30)\end{array}$ \\
\hline Interaction variables & & & & & \\
\hline $\begin{array}{l}\text { Within-individual victimization } \times \text { Workgroup } \\
\text { conflict }\end{array}$ & & $\begin{array}{l}-1.21 \\
(1.17)\end{array}$ & $\begin{array}{c}.32 \\
(.91)\end{array}$ & $\begin{array}{c}.08 \\
(1.00)\end{array}$ & $\begin{array}{l}-.45 \\
(.65)\end{array}$ \\
\hline $\begin{array}{l}\text { Within-individual victimization }{ }^{2} \times \text { Workgroup } \\
\text { conflict }\end{array}$ & & $\begin{array}{l}3.09 * \\
(1.43)\end{array}$ & $\begin{array}{c}1.64 \\
(1.36)\end{array}$ & $\begin{array}{c}.61 \\
(1.27)\end{array}$ & $\begin{array}{l}1.40 \\
(.96)\end{array}$ \\
\hline Mediator & & & & & \\
\hline Forgiveness & & & $\begin{array}{l}.13^{* *} \\
(.04)\end{array}$ & $\begin{array}{l}-.10^{*} \\
(.05)\end{array}$ & $\begin{array}{l}-.09 * \\
(.04)\end{array}$ \\
\hline Log Likelihood & $-497.52 * *$ & $-494.92 * *$ & $-392.81 * *$ & $-450.07 * *$ & $-413.96 * *$ \\
\hline $\mathrm{R}^{2}$ & .22 & .24 & .26 & .07 & .17 \\
\hline
\end{tabular}

Notes: $\dagger p<.10,{ }^{*} p<.05,{ }^{* *} p<.01$. Two-tailed. Within-employee $n=334$. Cross-employee $n=64 . \gamma$-coefficients are reported. The log likelihood is a measure of overall model goodness-of-fit. The log likelihood value is always negative, with higher values (closer to zero) indicating a better fitting model. 
Table 8

Study 3: Path Analytic Results

\begin{tabular}{|c|c|c|c|c|c|c|c|}
\hline & \multicolumn{2}{|c|}{ First Stage } & Second Stage & \multicolumn{2}{|c|}{ Direct Effects } & \multicolumn{2}{|c|}{ Indirect Effects } \\
\hline & $\mathrm{P}_{\mathrm{MX}}(\mathrm{SE})$ & $\mathrm{P}_{\mathrm{MX}}^{2}(\mathrm{SE})$ & $\mathrm{P}_{\mathrm{YM}} \quad(\mathrm{SE})$ & $(\mathrm{SE})$ & $\mathrm{P}_{\mathrm{YX}}^{2}(\mathrm{SE})$ & $\mathrm{P}_{\mathrm{YM}} \mathrm{P}_{\mathrm{MX}}$ Confidence Interval) & $\mathrm{P}_{\mathrm{YM}} \mathrm{P}_{\mathrm{MX}}{ }^{2}$ Confidence Interval $)$ \\
\hline Job Satisfaction & & & & & & & \\
\hline High group conflict & $-.98(.76)$ & $1.39(.84) \dagger$ & $.13(.04)^{* *}$ & $-.99(.37)^{*}$ & $.85(.50) \dagger$ & $-.13(-.04, .07)$ & $.18(-.03, .46)$ \\
\hline Low group conflict & $.23(.37)$ & $-1.70(.84)^{*}$ & $.13(.04)^{* *}$ & $-.99(.37)^{*}$ & $.85(.50) \dagger$ & $.03(-.07, .14)$ & $-.22(-.52,-.00) *$ \\
\hline \multicolumn{8}{|l|}{ Burnout } \\
\hline High group conflict & $-.98(.76)$ & $1.39(.84) \dagger$ & $-.10(.05)^{*}$ & $.71(.40) \dagger$ & $-.18(.44)$ & $.10(-.05, .33)$ & $-.14(-.41, .03)$ \\
\hline Low group conflict & $.23(.37)$ & $-1.70(.84)^{*}$ & $-.10(.05)^{*}$ & $.71(.40) \dagger$ & $-.18(.44)$ & $-.02(-.12, .06)$ & $.17(.00, .45)^{*}$ \\
\hline \multicolumn{8}{|l|}{ Turnover Intentions } \\
\hline High group conflict & $-.98(.76)$ & $1.39(.84) \dagger$ & $-.09(.04)^{*}$ & $.78(.25)^{* *}$ & $-.14(.30)$ & $.09(-.05, .29)$ & $-.12(-.37, .03)$ \\
\hline Low group conflict & $.23(.37)$ & $-1.70(.84)^{*}$ & $-.09(.04)^{*}$ & $.78(.25)^{* *}$ & $-.14(.30)$ & $-.02(-.11, .05)$ & $.15(-.04, .40)$ \\
\hline
\end{tabular}

Notes: $\dagger p<.10, * p<.05, * * p<.01$. Employees $n=334$. Group $n=64$. Coefficients in bold are significantly different across workgroup conflict levels $(p<.05)$. 
Figure 1

Proposed Theoretical Model

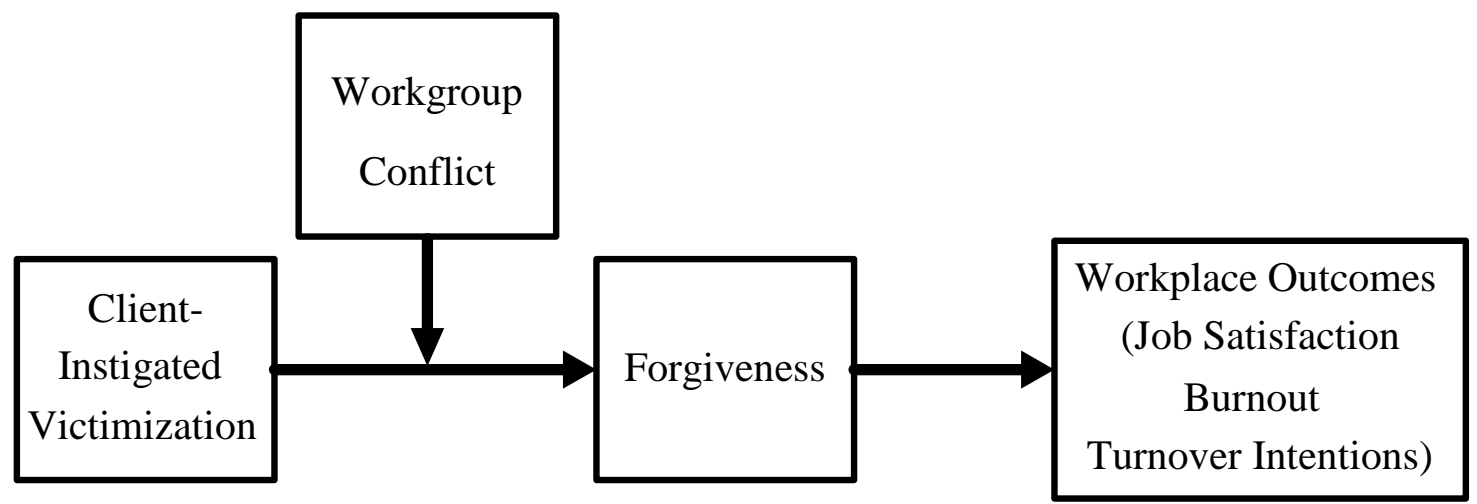

Figure 2

Forgiveness as a function of workgroup conflict and vicitimization severity

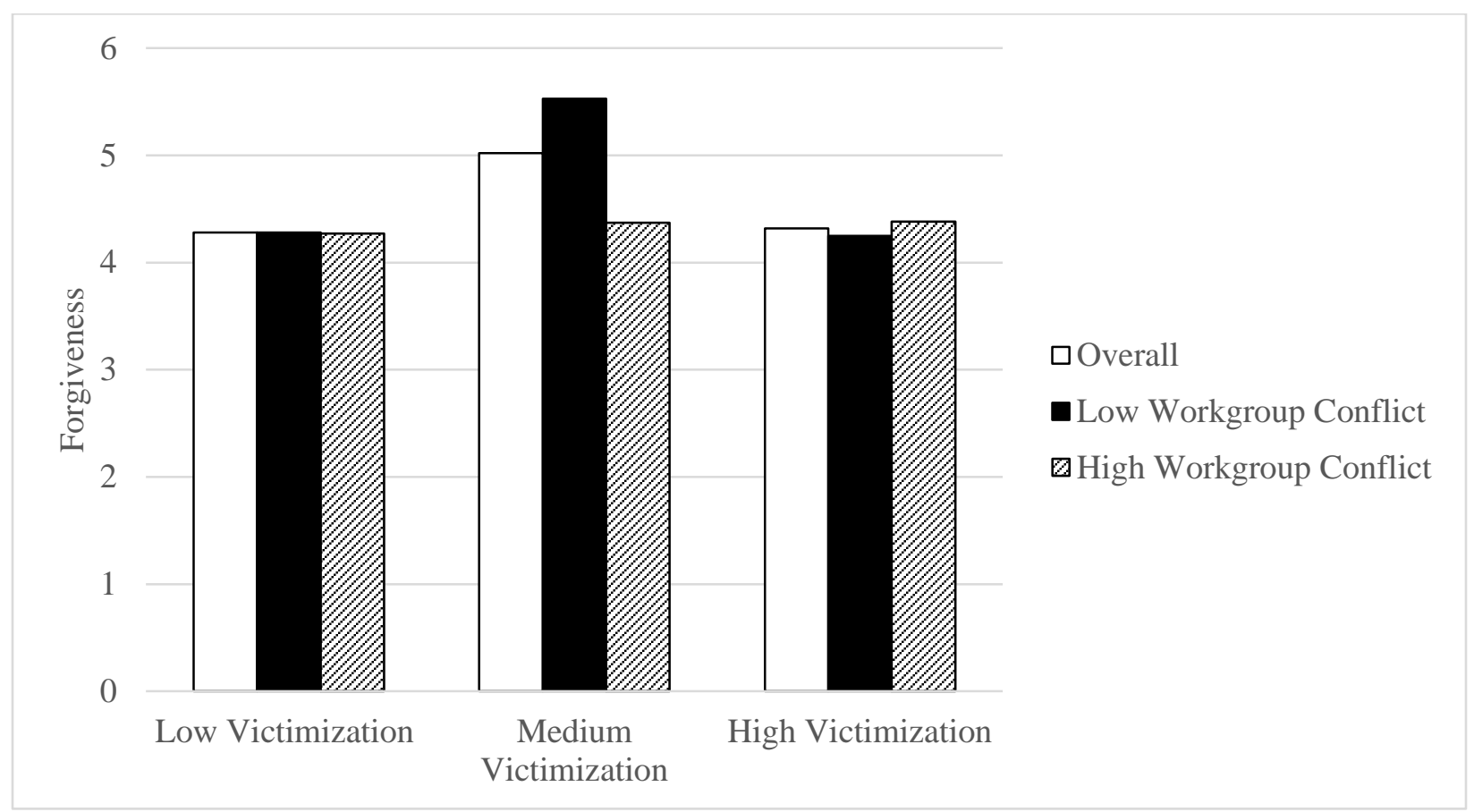


Figure 3

Study 2: The Relationship between Victimization and Forgiveness

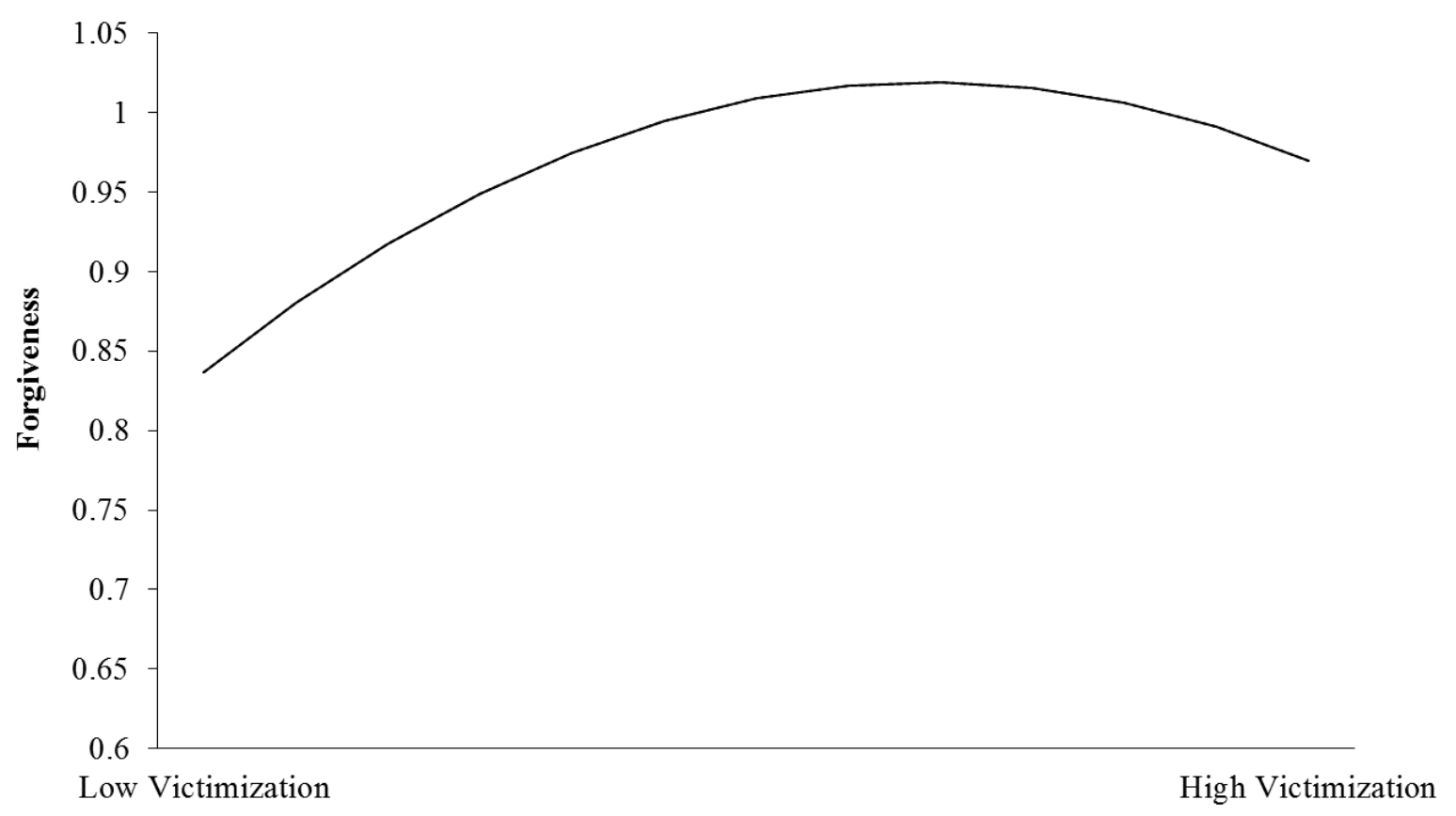

Figure 4

Study 2: The Relationship between Victimization and Forgiveness at Low and High Levels of Workgroup Conflict

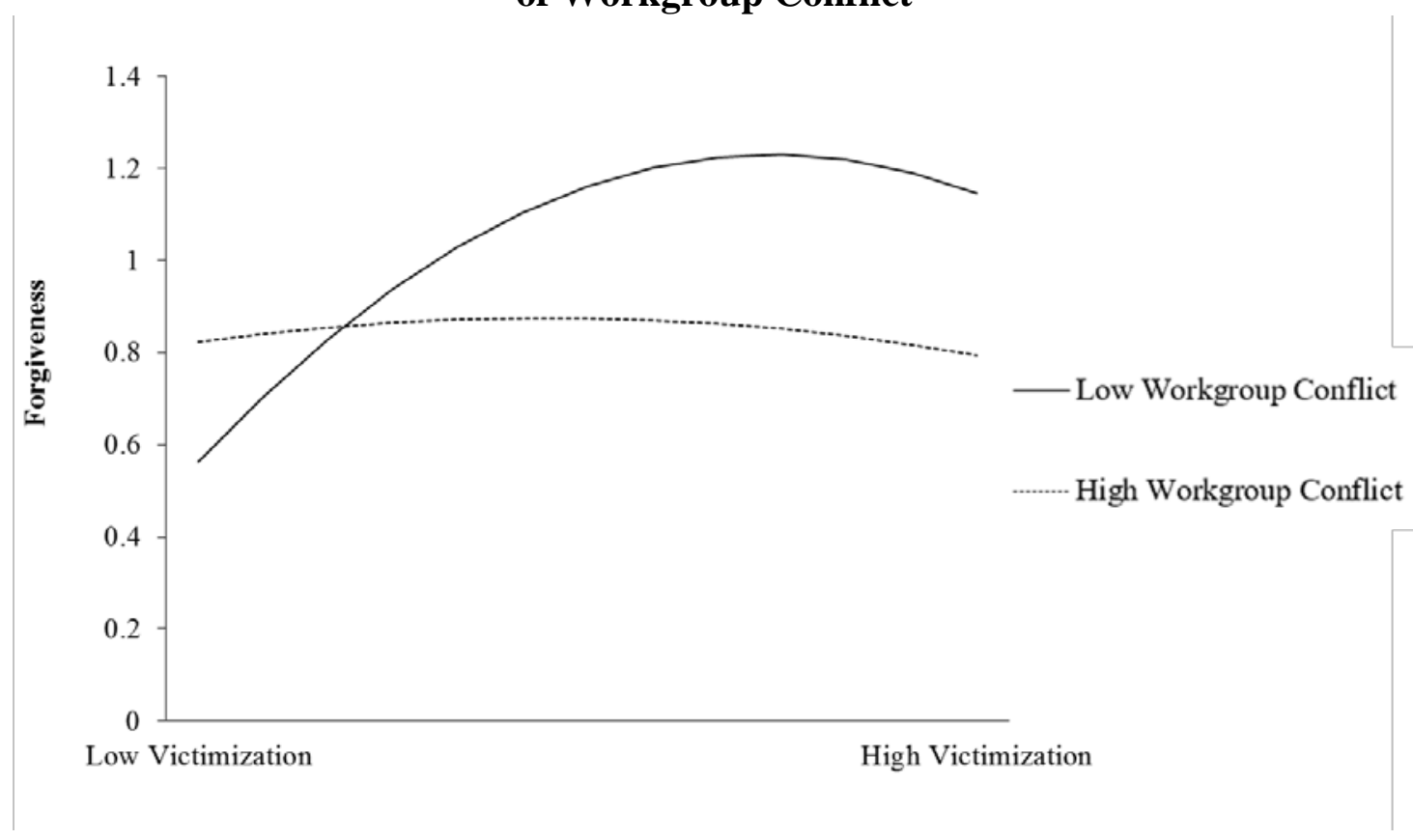




\section{Figure 5}

Study 2: The Total Effect of Victimization on Job Satisfaction via Forgiveness at Low and High Levels of Workgroup Conflict

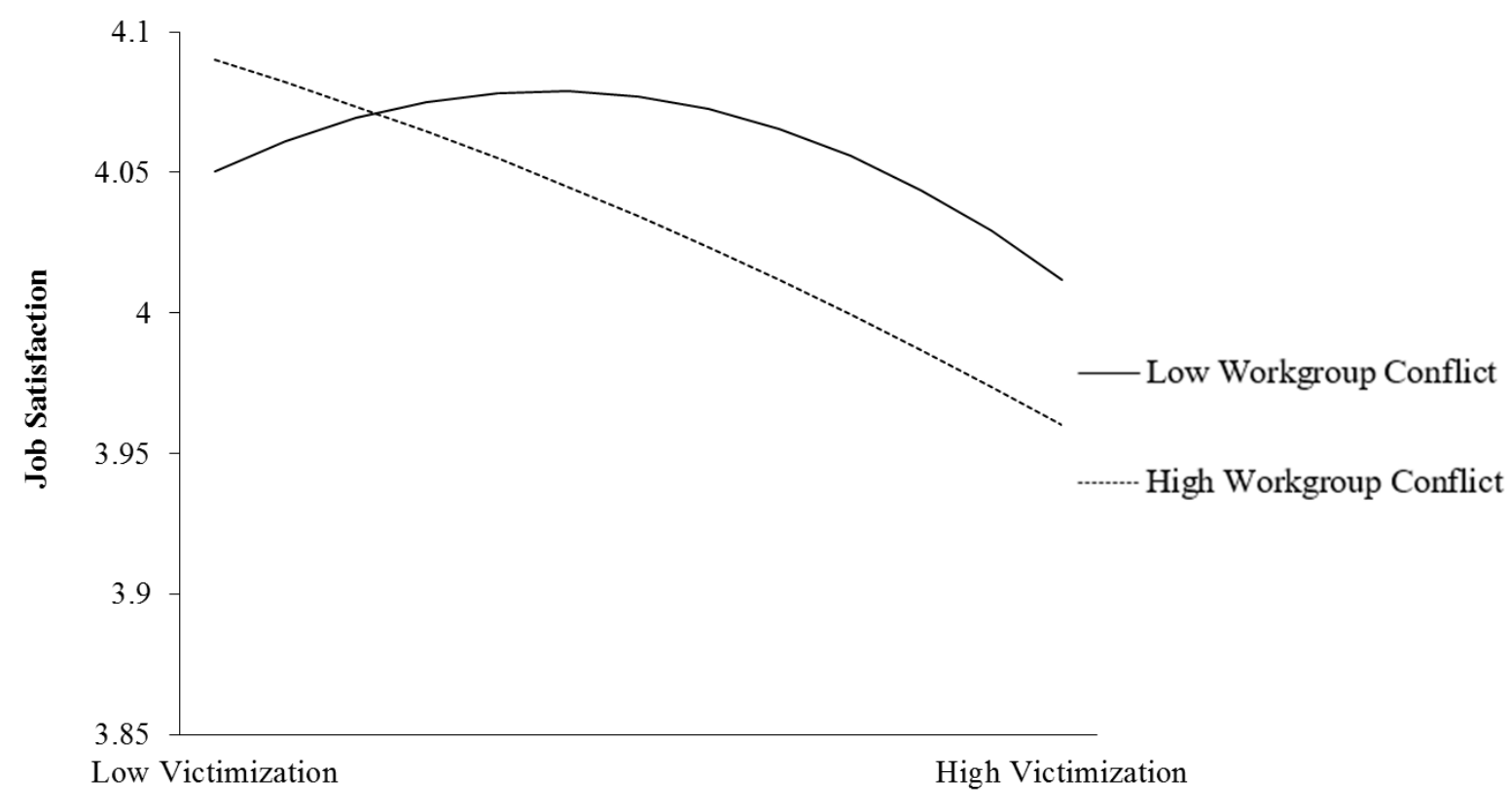

Figure 6

Study 2: The Total Effect of Victimization on Burnout via Forgiveness at Low and High Levels of Workgroup Conflict

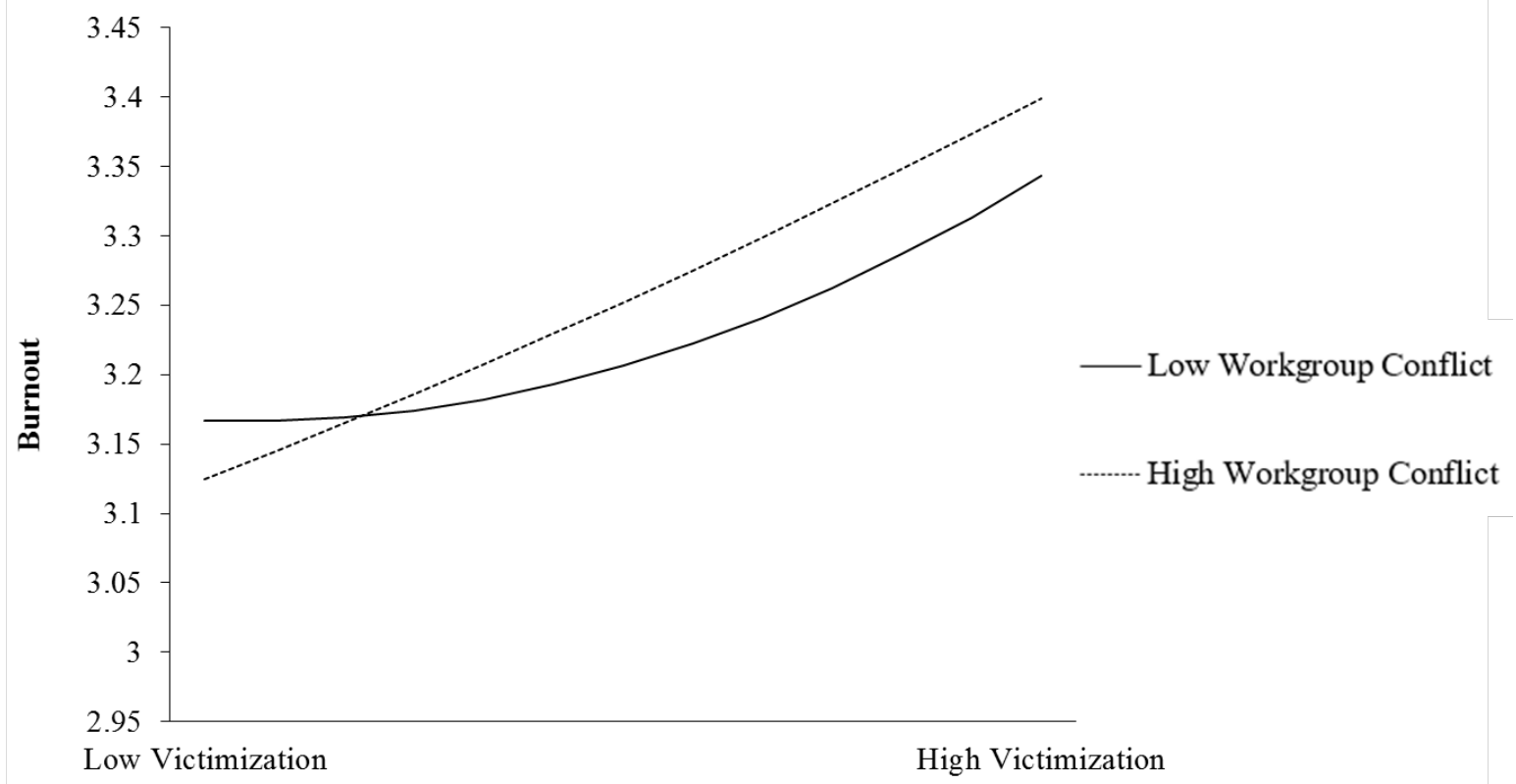




\section{Figure 7}

Study 2: The Total Effect of Victimization on Turnover Intention via Forgiveness at Low and High Levels of Workgroup Conflict

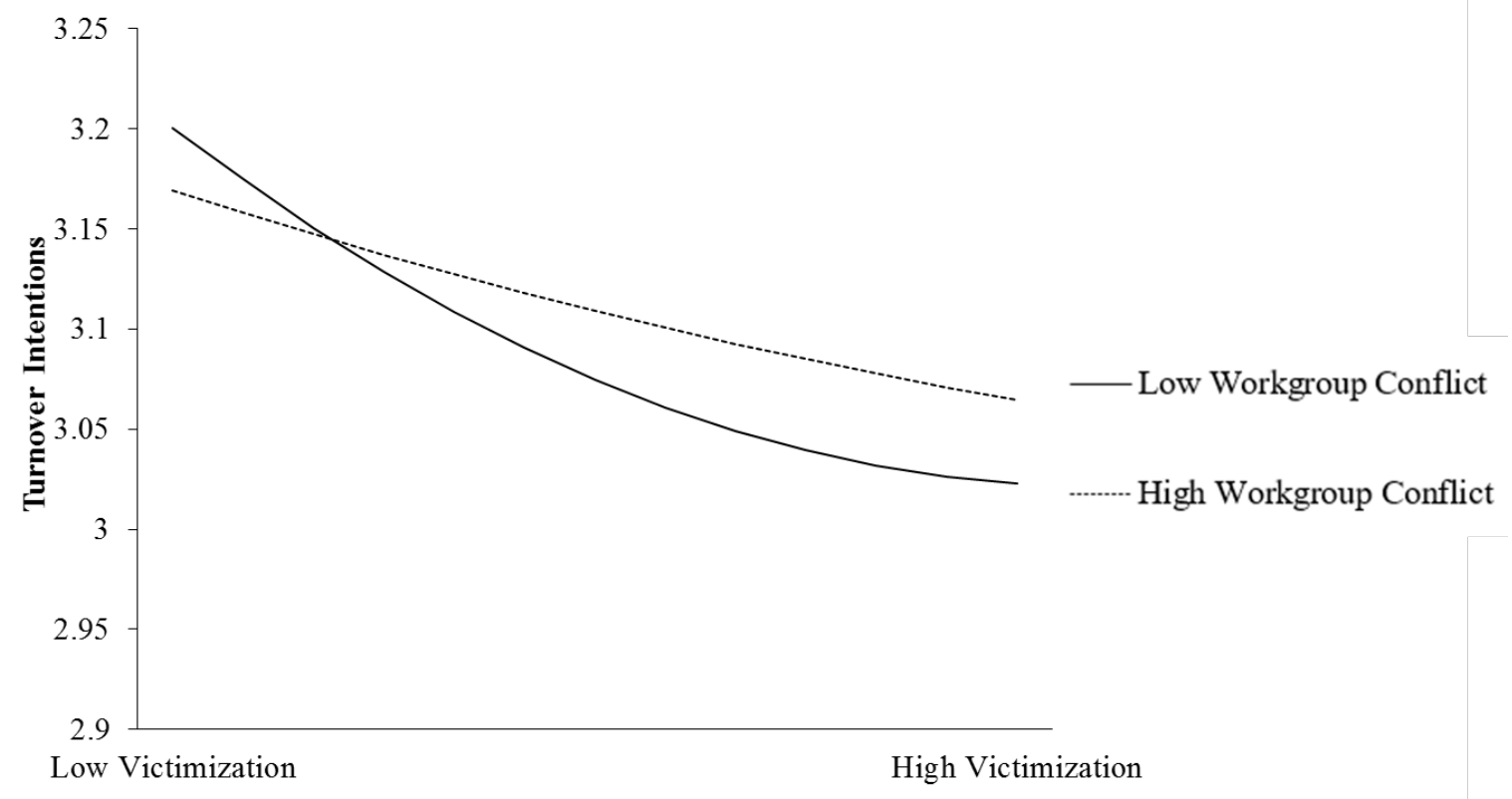

Figure 8

Study 3: The Relationship between Victimization and Forgiveness at Low and High Levels of Workgroup Conflict

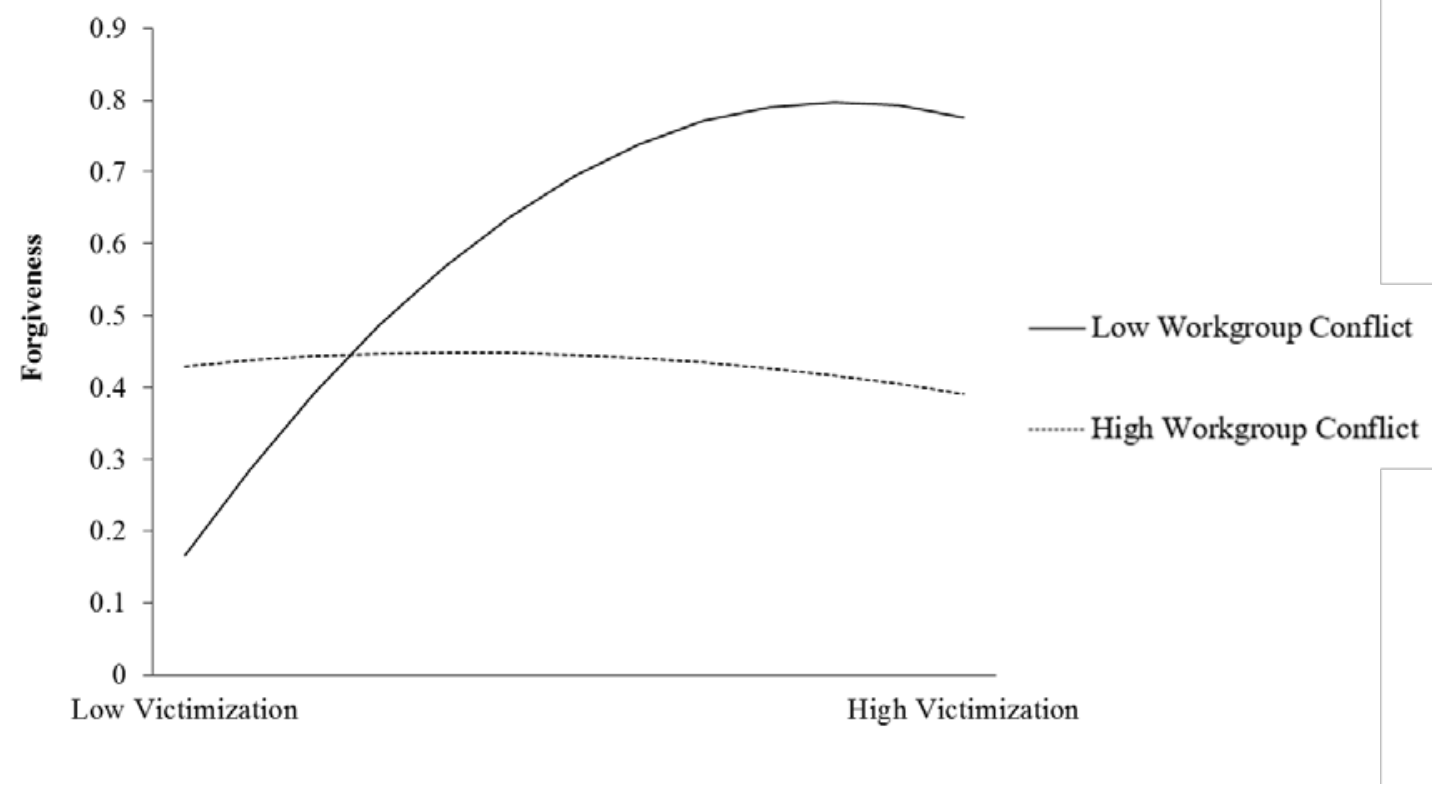




\section{Figure 9}

Study 3: The Total Effect of Victimization on Burnout via Forgiveness at Low and High Levels of Workgroup Conflict

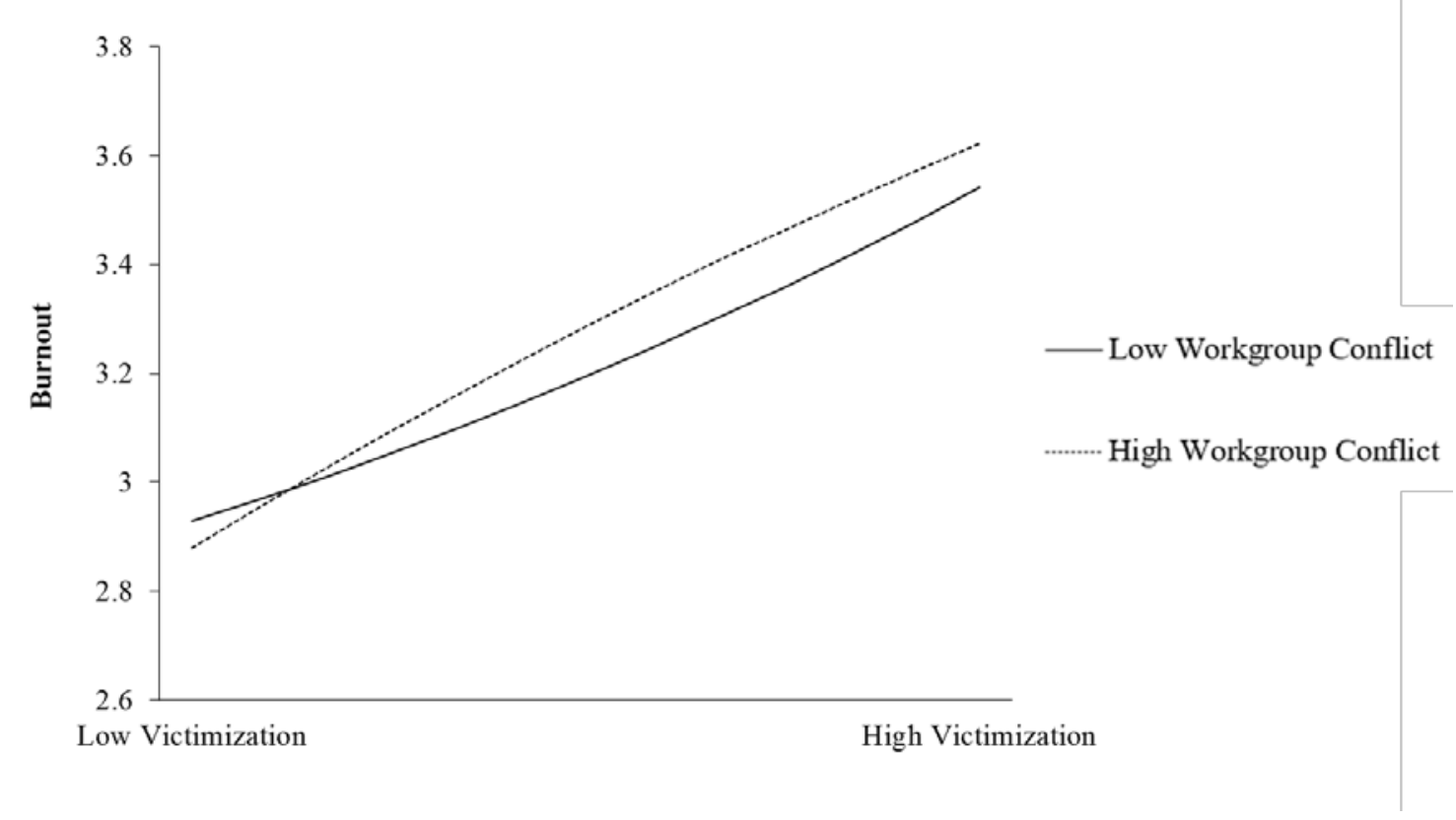

Figure 10

Study 3: The Total Effect of Victimization on Job Satisfaction via Forgiveness at Low and High Levels of Workgroup Conflict

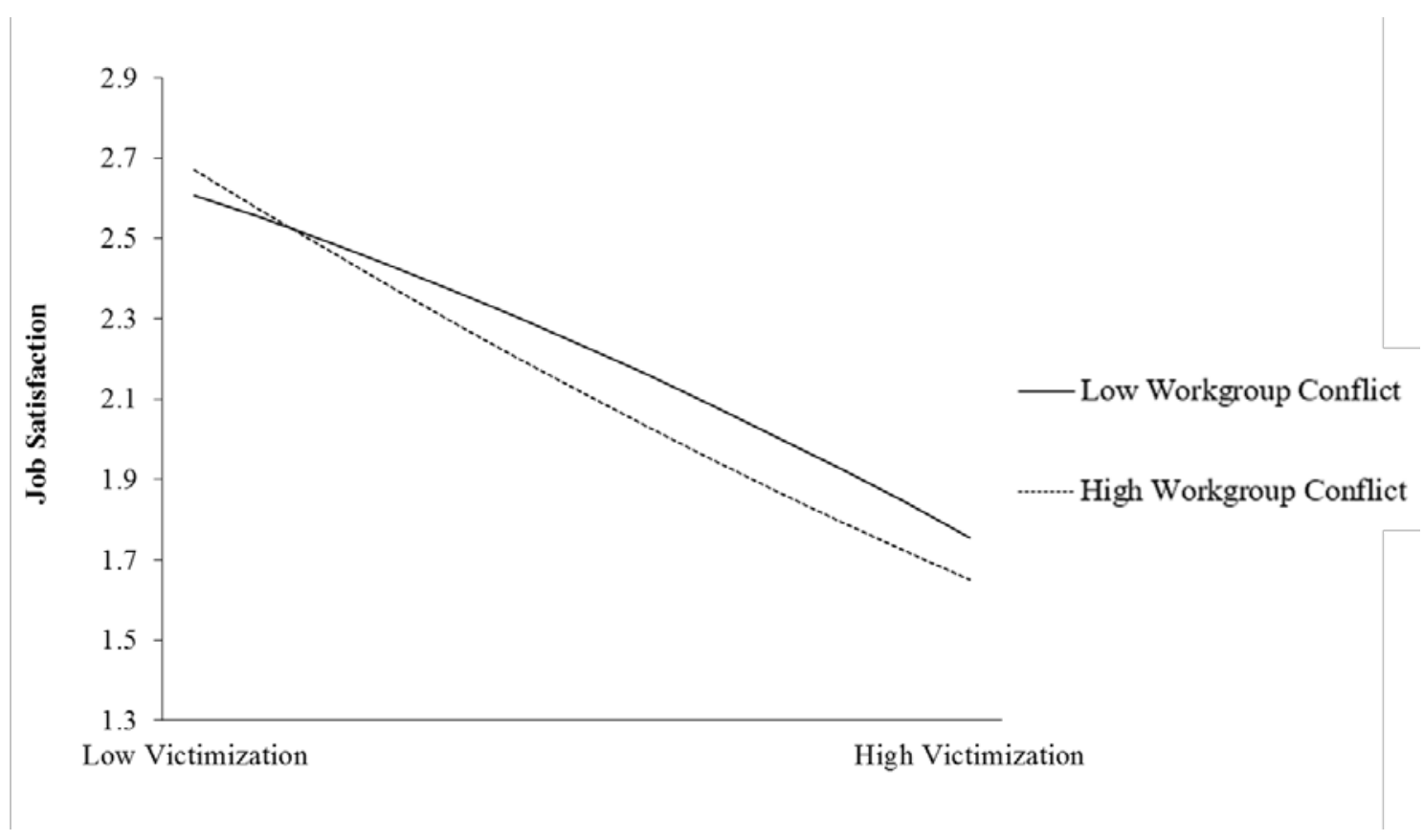




\section{Appendix}

In our two field studies, we dropped observations from our studies for participants who indicated that they had not experienced client-instigated victimization yet also indicated engaging in some level of forgiving their clients. We followed previous precedent in the literature as it is common for coping studies to only utilize participants who have indicated themselves as actual sufferers and, thus, have a need to cope (e.g., Nolen-Hoeksema, Parker, \& Larson, 1994; Wasti \& Cortina, 2002). Additionally, when we were theorizing, we had difficulty finding sufficient theoretical reasoning for why non-victimized employees should forgive others. According to COR, individuals engage in coping when they have encountered negative events in order to avoid stress and other negative consequences (Hobfoll, 1989; Hobfoll \& Shirom, 1993; Schaufeli \& Buunk, 2003). The definition of forgiveness as a coping mechanism specifies that forgiveness occurs as a response to a transgression (e.g., Gordon \& Baucom, 1998). Therefore, forgiveness as a coping option cannot occur unless the employee has been victimized. Thus, participants who did not encounter victimization would not be able to assess forgiveness as a coping mechanism because they had nothing to forgive.

If participants report practicing forgiveness, even when victimization is indicated as not having been experienced, one could argue that this suggests participants could be forgiving for other client transgressions not listed in the survey's victimization items or that they are reporting a trait-based tendency. However, the instructions in our paper-pencil field surveys explicitly asked participants to think about the negative workplace interactions that they had indicated as experiencing and to indicate their coping as a response to these specific negative interactions. Further, our research question specifically focuses on employees actually forgiving their clients and not their propensity to forgive. 
Nonetheless, to assuage any concern regarding dropping observations from analyses and potential range of restriction issues, we conducted analyses using the full sample which includes the employees with victimization score of 1 . The results are presented in the Tables A and B below. As the tables show, the results were largely consistent with the results obtained from the sample which excludes those employees with victimization score of 1. 
Table A. Study 2: Multilevel Linear Modeling Results using Full Sample

\begin{tabular}{|c|c|c|c|c|c|}
\hline & \multicolumn{2}{|c|}{ Forgiveness } & \multirow{2}{*}{$\begin{array}{c}\text { Job } \\
\text { Satisfaction } \\
\text { Model } 3 \\
\end{array}$} & \multirow{2}{*}{$\begin{array}{l}\text { Burnout } \\
\text { Model } 4 \\
\end{array}$} & \multirow{2}{*}{$\begin{array}{c}\text { Turnover } \\
\text { Intentions } \\
\text { Model } 5 \\
\end{array}$} \\
\hline & Model 1 & Model 2 & & & \\
\hline \multirow[t]{2}{*}{ Age } & .01 & .01 & .01 & .00 & $-.02 * * *$ \\
\hline & $(.01)$ & $(.01)$ & $(.01)$ & $(.00)$ & $(.01)$ \\
\hline \multirow[t]{2}{*}{ Education } & .10 & .09 & $-.24 * * *$ & $.11+$ & $.17^{*}$ \\
\hline & $(.06)$ & $(.06)$ & $(.06)$ & $(.07)$ & $(.08)$ \\
\hline \multirow[t]{2}{*}{ Tenure } & $-.02 *$ & $-.01 \dagger$ & -.01 & .01 & -.01 \\
\hline & $(.01)$ & $(.01)$ & $(.01)$ & $(.01)$ & $(.01)$ \\
\hline \multirow[t]{2}{*}{ Neuroticism } & -.13 & -.15 & $-.19 *$ & $.27 * *$ & .00 \\
\hline & $(.09)$ & $(.09)$ & $(.09)$ & $(.10)$ & $(.08)$ \\
\hline \multirow[t]{2}{*}{ Care for disabilities } & .00 & -.00 & -.04 & $.08+$ & -.01 \\
\hline & $(.05)$ & $(.05)$ & $(.04)$ & $(.04)$ & $(.04)$ \\
\hline \multirow[t]{2}{*}{ Shift size } & -.02 & -.01 & $.02 *$ & -.01 & $-.03 *$ \\
\hline & $(.01)$ & $(.01)$ & $(.01)$ & $(.01)$ & $(.01)$ \\
\hline \multirow[t]{2}{*}{ Agreeableness } & $.23^{*}$ & $.24^{*}$ & -.10 & -.07 & -.06 \\
\hline & $(.11)$ & (.11) & $(.09)$ & $(.09)$ & $(.09)$ \\
\hline \multirow[t]{2}{*}{ Between-group victimization } & $1.42 *$ & $1.85^{* *}$ & .70 & .29 & -.17 \\
\hline & $(.69)$ & $(.66)$ & $(.68)$ & $(.56)$ & $(.58)$ \\
\hline \multirow[t]{2}{*}{ Between-group victimization ${ }^{2}$} & $-.23+$ & $-.32 *$ & -.21 & .02 & .06 \\
\hline & $(.14)$ & $(.13)$ & $(.14)$ & $(.11)$ & $(.12)$ \\
\hline \multicolumn{6}{|l|}{ Independent variables } \\
\hline \multirow[t]{2}{*}{ Workgroup conflict } & -.07 & -.21 & $-.58 * * *$ & $.37 * *$ & $.49 * *$ \\
\hline & $(.12)$ & $(.13)$ & $(.15)$ & $(.14)$ & $(.15)$ \\
\hline \multirow[t]{2}{*}{ Within-group victimization } & .06 & .10 & -.07 & $.17^{*}$ & -.01 \\
\hline & $(.07)$ & $(.09)$ & $(.08)$ & $(.08)$ & $(.07)$ \\
\hline \multirow[t]{2}{*}{ Within-group victimization ${ }^{2}$} & $-.10 *$ & $-.17^{*}$ & -.00 & .01 & .04 \\
\hline & $(.05)$ & $(.07)$ & $(.06)$ & $(.04)$ & $(.04)$ \\
\hline \multicolumn{6}{|l|}{ Interaction variables } \\
\hline \multirow[t]{2}{*}{ Within-group victimization $\times$ Workgroup conflict } & & -.23 & -.20 & .07 & .07 \\
\hline & & $(.16)$ & $(.15)$ & $(.17)$ & $(.12)$ \\
\hline \multirow[t]{2}{*}{ Within-group victimization ${ }^{2} \times$ Workgroup conflict } & & $.19 *$ & .08 & .01 & -.04 \\
\hline & & $(.11)$ & $(.11)$ & $(.07)$ & $(.07)$ \\
\hline \multicolumn{6}{|l|}{ Mediator } \\
\hline \multirow[t]{2}{*}{ Forgiveness } & & & $.11^{*}$ & $-.12 *$ & -.07 \\
\hline & & & $(.05)$ & $(.06)$ & $(.06)$ \\
\hline Log Likelihood & $-383.30 * *$ & $-381.64 * *$ & $-339.62 * *$ & $-360.54 * *$ & $-349.07 * *$ \\
\hline $\mathrm{R}^{2}$ & .11 & .12 & .26 & .23 & .26 \\
\hline
\end{tabular}

Notes: $\dagger p<.10, * p<.05, * * p<.01, * * * p<.001$. (one-tailed test). Employees $n=261$. Group $n=54$. $\gamma$-coefficients are reported. The log likelihood is a measure of overall model goodness-of-fit. The log likelihood value is always negative, with higher values (closer to zero) indicating a better fitting model. 
Table B. Study 3: Multilevel Linear Modeling Results using Full Sample

\begin{tabular}{|c|c|c|c|c|c|}
\hline & \multicolumn{2}{|c|}{ Forgiveness } & \multirow{2}{*}{$\begin{array}{c}\text { Job } \\
\text { Satisfaction } \\
\text { Model } 3 \\
\end{array}$} & \multirow{2}{*}{$\begin{array}{l}\text { Burnout } \\
\text { Model } 4 \\
\end{array}$} & \multirow{2}{*}{$\begin{array}{c}\text { Turnover } \\
\text { Intentions } \\
\text { Model } 5 \\
\end{array}$} \\
\hline & Model 1 & Model 2 & & & \\
\hline \multirow[t]{2}{*}{ Age } & .01 & .01 & .02 & -.01 & $-.03+$ \\
\hline & $(.02)$ & $(.02)$ & $(.01)$ & $(.02)$ & $(.02)$ \\
\hline \multirow[t]{2}{*}{ Education } & $.75 * * *$ & $.74 * * *$ & -.06 & .06 & .00 \\
\hline & $(.15)$ & $(.15)$ & $(.11)$ & $(.14)$ & $(.11)$ \\
\hline \multirow[t]{2}{*}{ Tenure } & .01 & .01 & .00 & -.02 & $-.02+$ \\
\hline & $(.02)$ & $(.02)$ & $(.01)$ & $(.01)$ & $(.01)$ \\
\hline \multirow[t]{2}{*}{ Neuroticism } & -.23 & -.23 & -.09 & .27 & .14 \\
\hline & $(.22)$ & $(.22)$ & (.12) & (.19) & $(.13)$ \\
\hline \multirow[t]{2}{*}{ Agreeableness } & $.32+$ & $.32+$ & $.20+$ & $.30 *$ & .03 \\
\hline & (.19) & $(.19)$ & (.11) & $(.14)$ & $(.10)$ \\
\hline \multirow[t]{2}{*}{ Revenge } & .18 & .17 & -.06 & -.00 & -.08 \\
\hline & (.13) & $(.13)$ & (.09) & $(.15)$ & $(.11)$ \\
\hline \multirow[t]{2}{*}{ Between-individual victimization } & 6.14 & 5.11 & $-15.21 *$ & .09 & .79 \\
\hline & (9.52) & (9.87) & (6.48) & (7.02) & (6.90) \\
\hline \multirow[t]{2}{*}{ Between-individual victimization ${ }^{2}$} & -1.77 & -1.37 & $5.48 *$ & .43 & .24 \\
\hline & (3.65) & (3.80) & (2.46) & $(2.70)$ & (2.61) \\
\hline \multicolumn{6}{|l|}{ Independent variables } \\
\hline \multirow[t]{2}{*}{ Workgroup conflict } & $-.49 *$ & $-.54 * *$ & -.13 & $-.24+$ & -.14 \\
\hline & $(.20)$ & $(.20)$ & $(.12)$ & $(.15)$ & $(.11)$ \\
\hline \multirow[t]{2}{*}{ Within-individual victimization } & .21 & .16 & $-.63 * * *$ & $.62^{* *}$ & $1.06 * * *$ \\
\hline & $(.26)$ & $(.27)$ & $(.19)$ & $(.23)$ & $(.23)$ \\
\hline \multirow[t]{2}{*}{ Within-individual victimization ${ }^{2}$} & $-.58+$ & $-.64 *$ & .40 & -.20 & -.50 \\
\hline & $(.34)$ & $(.31)$ & $(.32)$ & $(.30)$ & $(.47)$ \\
\hline \multicolumn{6}{|l|}{ Interaction variables } \\
\hline \multicolumn{2}{|c|}{$\begin{array}{l}\text { Within-individual victimization } \times \text { Workgroup } \\
\text { conflict }\end{array}$} & .38 & .11 & $-.80 * *$ & -.07 \\
\hline & & $(.35)$ & $(.28)$ & $(.29)$ & $(.32)$ \\
\hline \multirow[t]{2}{*}{$\begin{array}{l}\text { Within-individual victimization }{ }^{2} \times \\
\text { conflict }\end{array}$} & & $1.86^{* *}$ & 1.20 & 1.10 & .91 \\
\hline & & $(.70)$ & $(.92)$ & $(.84)$ & (1.19) \\
\hline \multicolumn{6}{|l|}{ Mediator } \\
\hline \multirow[t]{3}{*}{ Forgiveness } & & & $.12^{* * *}$ & .02 & -.01 \\
\hline & & & $(.03)$ & $(.05)$ & $(.03)$ \\
\hline & - & - & & - & \\
\hline Log Likelihood & $1178.51^{* *}$ & $1175.78 * *$ & $-943.73 * *$ & $1024.41^{* *}$ & $-957.12 * *$ \\
\hline $\mathrm{R}^{2}$ & .24 & .25 & .27 & .10 & .16 \\
\hline
\end{tabular}

Notes: $\dagger p<.10, * p<.05, * * p<.01, * * * p<.001$. (two-tailed test). Within-employee $n=748$. Cross-employee $n=$ 80. $\gamma$-coefficients are reported. The log likelihood is a measure of overall model goodness-of-fit. The log likelihood value is always negative, with higher values (closer to zero) indicating a better fitting model. 